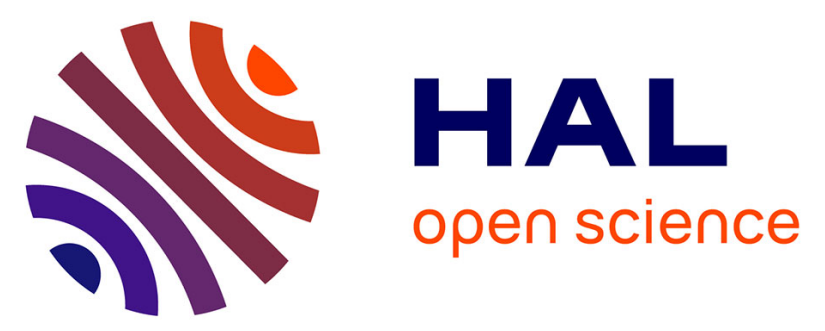

\title{
Failure mode analysis of SMAW welded UNS N08028 (Alloy28) superaustenitic stainless steel under crack growth tests
}

\author{
Yacine Kchaou, Véronique Pelosin, Gilbert Hénaff, Nader Haddar, Khaled
} Elleuch

\section{To cite this version:}

Yacine Kchaou, Véronique Pelosin, Gilbert Hénaff, Nader Haddar, Khaled Elleuch. Failure mode analysis of SMAW welded UNS N08028 (Alloy28) superaustenitic stainless steel under crack growth tests. Engineering Failure Analysis, 2019, 97, pp.804-819. 10.1016/j.engfailanal.2019.01.067 . hal02282582

\section{HAL Id: hal-02282582 \\ https://hal.science/hal-02282582}

Submitted on 21 Oct 2021

HAL is a multi-disciplinary open access archive for the deposit and dissemination of scientific research documents, whether they are published or not. The documents may come from teaching and research institutions in France or abroad, or from public or private research centers.
L'archive ouverte pluridisciplinaire HAL, est destinée au dépôt et à la diffusion de documents scientifiques de niveau recherche, publiés ou non, émanant des établissements d'enseignement et de recherche français ou étrangers, des laboratoires publics ou privés.

\section{()ㅜ(1)}

Distributed under a Creative Commons Attribution - NonCommercial| 4.0 International 


\title{
Failure mode analysis of SMAW welded UNS N08028 (Alloy28) superaustenitic stainless steel under crack growth tests
}

\author{
Yacine Kchaou a,b, Véronique Pelosin a, Gilbert Hénaff a, Nader Haddar ${ }^{\text {b }}$, Khaled \\ Elleuch $^{b}$
}

a Institut Pprime, Département Physique et Mécanique des Matériaux, UPR 3346 CNRS ISAE-ENSMA Université de Poitiers, Téléport 2, 1, avenue Clément Ader, BP 40109, F - 86961 Futuroscope Chasseneuil Cedex, France

b Laboratoire de Génie des Matériaux et Environnement (LGME), ENIS, BPW 1173, Sfax, Tunisia

*Corresponding author. Tel : +33 (0) 616112082 Fax : +33 (0) 549498291.

Email : yacinekchaou@yahoo.fr

\begin{abstract}
The Fatigue Crack Growth (FCG) behavior of welded UNS N08028 (Alloy28) superaustenitic stainless steel was investigated in this paper. Alloy28 superaustenitic stainless steel was welded using Shielded Metal Arc Welding process. The FCG behavior was studied under two load ratios $(0.1$ and 0.5$)$ and for different specimen configuration: Base Metal (BM), Weld Metal (WM) and Welded Joint (WJ). The results indicated that FCG rates of WM specimen is lower than BM specimen at $\mathrm{R}=0.1$. Moreover, load ratio affects the FCG rate for BM and WM specimen. In addition, the observation of fatigue crack growth path of WM displayed that crack follows dendritic orientation giving a tortuous crack path, while it is less tortuous for BM specimens. Scanning Electron Microscope (SEM) observations of BM fractured surfaces showed that damage mechanism is intergranular for lower $\Delta \mathrm{K}$ value, and transgranular for higher $\Delta \mathrm{K}$ value. Moreover, SEM observations of WM fractured surface showed the presence of welding defects which can affect negatively fatigue crack growth resistance at $\mathrm{R}=0.5$.
\end{abstract}

\section{Introduction}

Superaustenitic stainless steels are widely used in the pressure vessel manufacturing. Their high mechanical and corrosion resistances make them the most used stainless steels for this application and they can be welded to assembly different structures. Welded zone is considered as a mechanical and microstructural heterogeneity which can affect fatigue resistance of the component during cyclic loading. Numerous investigations focused on fatigue resistance of welded austenitic stainless steel and especially their fatigue crack growth behavior [1-5]. They showed that crack growth rate is faster in Base Metal than Weld Metal. Tsay et al. investigated the FCG behavior of AISI 304 stainless steel in air and $\mathrm{H}_{2}$ [3]. They showed that the faster FCG rate of Base Metal compared to Weld Metal is caused by the presence of compressive residual stresses in the Weld Metal crack tip. Authors showed also that this result is due to a tortuous crack path and the high roughness of Weld Metal fractured 
surface. Li et al. investigated FCG behavior of a welded ferritic-martensitic cold rolled DP780 dual phase steel at room temperature [6]. Authors found that Weld Metal has a FCG rate lower than Base Metal. They showed that this result is due to the hard martensite microstructure, which limits the size of the plastic zone at the crack tip. Deng et al. investigated FCG behavior of dissimilar $9 \mathrm{Cr} / \mathrm{CrMoV}$ welded joint using different stress ratio and specimen configuration [7]. They found that stress ratio affects FCG of Base Metal, Weld Metal and Heat Affected Zone (HAZ). This is due to the presence of crack closure induced by plasticity. Authors found also that Weld Metal has a better FCG resistance compared to Base Metal and HAZ because of the presence of a tortuous crack path. Al-Haidary et al. investigated Fatigue Crack Growth (FCG) behavior of welded 316L stainless steel at room temperature [8]. They pointed out the good resistance of Base Metal to crack propagation compared to Weld Metal. This is mainly due to the presence of tensile residual stress in welded zone.

In this context, this paper investigates FCG behavior of welded Alloy 28 superaustenitic stainless steel at room temperature. Microstructure, micro-hardness profile and tensile properties were analyzed on Base Metal and Weld Metal. The FCG rate on Base Metal, Weld Metal and Welded Joint specimens were determined for two different load ratios. Subsequently, morphological observations of fractured specimen and crack path were performed to better analyze the FCG behavior and failure mode.

\section{Materials and methods}

Hot rolled Alloy28 superaustenitic stainless steel sheets were used in this study. Alloy28 sheets were welded using Shielded Metal Arc Welding (SMAW) process in order to manufacture pressure vessels. Welding was made on Base Metal using commercially available filler metal (Sanicro 28). The stainless steel sheets were first prepared by chamfering and grinding the edges in order to make an $\mathrm{X}$ form. The industrial welding parameters and the heat input in each block of the 15 welding passes are given in Table 1. Metallographic observations were carried out on several specimens prepared by grinding using 120, 240, 320, 600, 800, 1000, 2000 and 4000 grits of SiC papers, followed by the final polishing with $3 \mu \mathrm{m}$ and $1 \mu \mathrm{m}$ alumina powders. Then, specimens were etched using electrolytic etching in an aqueous solution of $10 \%$ wt. of oxalic acid at $5 \mathrm{~V}$ during 20 seconds. Microstructure was investigated using optical microscope and Scanning Electron Microscope (SEM) equipped with energy dispersive spectroscopy (EDS) point analysis. Micro-indentation 
Vickers hardness tests were performed on Base Metal and weld Weld Metal at a load of 300 mN using a microhardness Fischer HM T3 XY-prog model.

Tensile tests were carried out at room temperature on cylindrical specimens machined in Base Metal and Weld Metal using an axial servo-electric machine (Instron $1362100 \mathrm{kN}$ ) with a load train and compact digital electronics control. Base Metal specimens were taken along the rolling direction of the Alloy28 sheets. Tensile samples have a cylindrical form with a diameter of $4.3 \mathrm{~mm}$ and a length of $56 \mathrm{~mm}$. Weld Metal samples were machined in the welding direction. WJ specimens were welded perpendicularly to welding direction and contain a $5 \mathrm{~mm}$ weld nugget in its center. For all tests, the applied strain rate was equal to $10^{-3}$ $\mathrm{s}^{-1}$ and the strain was measured using an extensometer with a gauge length of $12.5 \mathrm{~mm}$. Tensile tests were performed following the standard ASTM: E8/E8M - 16a Standard Test Methods for Tension Testing of Metallic Materials. FCG tests were conducted on a servohydraulic test machine at room temperature in a laboratory air environment (Fig.1). FCG tests were performed according to ASTM E647 under constant load control with a sinusoidal loading waveform at a frequency of $20 \mathrm{~Hz}$ and load ratio ranging from 0.1 to 0.5 . Crack length was measured continuously by the compliance method with a crack mouth clip gauge. Optical measurements were periodically taken to calibrate the compliance method. A Compact Tension (CT) specimen with a $32 \mathrm{~mm}$ width, $8 \mathrm{~mm}$ thickness was used. Fig. 2 shows an illustration of the tested sample, including its dimensions. Three types of CT configuration were machined following different direction as shown in Fig. 3 a), b) and c) respectively: in the L-T direction in order to have a notch axis perpendicular to the rolling direction, named CT-BM, CT specimens notched in the weld metal named CT-WM, and CT specimens notched perpendicularly to Weld Metal named CT-WJ.

\section{Results and discussions}

\subsection{Microstructure, Hardness profile and tensile properties}

Chemical composition of Base Metal, Weld Metal and filler metal are showed in Table 2. It can be seen that $\mathrm{Cr}$ and $\mathrm{Ni}$ content are similar in Base Metal and Weld Metal which lead them compatible to welding. Optical micrographs showing the microstructure of Base Metal and Weld Metal are displayed in Fig. 4. The microstructure of Base Metal is fully austenitic and no delta ferrite or carbide precipitates were observed. The microstructure consists of equiaxed grains and twins and they can be observed in the austenitic matrix. The austenitic grains are randomly oriented with sizes range between $100 \mu \mathrm{m}$ and $200 \mu \mathrm{m}$. The microstructure of Weld 
Metal presents dendritic grains oriented following welding passes direction. The microhardness profile across the weld bead is shown in Fig. 5. It can be noted that the hardness value of Weld Metal reaches $330 \mathrm{HV}$ at the middle of the welding then decreases unto $220 \mathrm{HV}$ in the Base Metal. The tensile properties of Base Metal and Weld Metal are showed in Fig. 6. Both of the tested materials present a ductile behavior but the mechanical properties are different. Indeed, it can be found that yield stress and tensile strength of Base Metal are lower than Weld Metal. Meanwhile, the elongation of Base Metal is also much higher than Weld Metal (A\% $=15.2 \%$ and $7.5 \%$ respectively) which can be confirmed by the necking coefficient value ( $\mathrm{Z} \%=62 \%$ and $41 \%$ respectively).

\subsection{Fatigue Crack Growth tests on Alloy28 Base Metal (CT-BM)}

\subsubsection{FCG tests results}

In order to study the effect of load ratio on FCG rate, Fatigue Crack Growth tests were carried out on CT-BM specimens with a load ratio equal to 0.1 and 0.5 . The evolutions of crack length versus the number of cycles as well as FCG rate $(\mathrm{da} / \mathrm{dN})$ versus stress intensity factor $\Delta \mathrm{K}$ were depicted in Fig. 7 and 8 respectively. Crack growth rate was determined using the Eq. 1:

$$
\frac{d a}{d N}=\frac{a_{i+1}-a_{i}}{N_{i+1}-N_{i}}
$$

$\mathrm{a}_{\mathrm{i}}$ and $\mathrm{N}_{\mathrm{i}}$ are the crack length and number of cycles at the measurement time $i$ respectively.

The stress intensity factor amplitude $\Delta \mathrm{K}$ for $\mathrm{CT}$ specimens could be calculated according to Eq. 2. [9] :

$$
\Delta K=\frac{\Delta P}{B \sqrt{W}} \times \frac{(2+\alpha)\left(0,886+4,64 \alpha-13,31 \alpha^{2}+14,72 \alpha^{3}-5,6 \alpha^{4}\right)}{(1-\alpha)^{\frac{3}{2}}}
$$

where $\mathrm{B}$ is the specimen thickness, $\mathrm{W}$ is the specimen width, $\Delta \mathrm{P}$ is the applied loading amplitude, $\alpha$ is the fatigue crack coefficient defined by $\frac{a}{W}$ and $a$ is the crack length.

Generally, the fatigue crack growth process can be divided into three regions: slow expanding region (I), stable expanding region (II) and rapid expanding region (III). In this study, the tests were mainly performed in the region (II), which is the most valuable to estimate the fatigue life. The conventional Paris model [10-12], given by Eq. (3), was applied to describe the FCG behavior of the investigated steels: 


$$
\frac{d a}{d N}=C(\Delta K)^{m}
$$

$\mathrm{da} / \mathrm{dN}$ is the Fatigue Crack Growth rate, $\Delta \mathrm{K}$ is the stress intensity factor range, $\mathrm{C}$ and $\mathrm{m}$ are constants that depend on the tested materials.

The Fatigue Crack Growth rate data for CT-BM specimens are summarized in Fig. 8 in terms of the relationship between the FCG rates $(\mathrm{da} / \mathrm{dN})$ and stress intensity factor $(\Delta \mathrm{K})$. Paris law parameters extracted from $\mathrm{da} / \mathrm{dN}$ curves are reported in Table 3. It can be seen that FCG rate is higher for $\mathrm{R}=0.5$ test. For example, for $\Delta \mathrm{K}=15 \mathrm{MPa} \sqrt{\mathrm{m}}, \mathrm{da} / \mathrm{dN}=1.3 \times 10^{-8} \mathrm{~m} / \mathrm{cycle}$ at $\mathrm{R}=$ 0.5 and $\mathrm{da} / \mathrm{dN}=3 \times 10^{-9} \mathrm{~m} /$ cycle at $\mathrm{R}=0.1$. In order to understand the origin of the difference between FCG rate at $\mathrm{R}=0.1$ and 0.5 and to clarify the fatigue fracture process, examinations of the fatigue fracture surfaces of Base Metal specimens are essential.

\subsubsection{Morphological analysis of CT-BM specimens}

The fatigue crack growth path and fractography observations could be used to reveal the microstructure detail where crack grows through, to identify the characteristics of the FCG as well and the fine-scale fatigue fracture features. Therefore, optical microscopy of crack path and SEM observations of fractured CT-BM specimens tested at $\mathrm{R}=0.1$ and $\mathrm{R}=0.5$ were carried out.

Fig. 9 shows the crack path observation of CT-BM specimen tested at $\mathrm{R}=0.5$. It can be seen that crack path presents few deviations with some crack branching. Moreover, it seems that at lower $\Delta \mathrm{K}$ value (10 and $11 \mathrm{MPa} \sqrt{\mathrm{m}}$ ), crack path is dependent on microstructure and propagates in grain or twin boundaries. For higher $\Delta \mathrm{K}$ value, crack propagates and crosses grains and twins giving a transgranular propagation mode.

Figs. 10 show SEM observations of fractured CT-BM specimen tested at $\mathrm{R}=0.5$ for different $\Delta \mathrm{K}$ values. At $\Delta \mathrm{K}=11 \mathrm{MPa} \sqrt{\mathrm{m}}\left(\mathrm{da} / \mathrm{dN}=3.2 \times 10^{-9} \mathrm{~m} /\right.$ cycle $)$, local propagation is observed on a grain or twin, which confirm a transgranular propagation mode. At $\Delta \mathrm{K}=15$ and $20 \mathrm{MPa} \sqrt{\mathrm{m}}$, fractured surface presents several cleavage facets, relief appearance and secondary cracks.

Concerning test performed at $\mathrm{R}=0.1$, optical micrographs were performed on fractured surface and crack path of CT-BM specimen (Fig. 11 a) and b)). It can be seen that fractured surface presents a high roughness aspect. As shown in Fig. 11 b), the crack propagation path contains few deflections and crack branching. Compared to CT-BM specimen tested at $\mathrm{R}=$ 0.5 , crack propagation path at $\mathrm{R}=0.1$ presents slightly higher deflections. Severe crack 
deflections in coarse-grained materials make the fracture surfaces rougher and result in an elevated degree of mismatch between the matching cracked surfaces. Moreover, it leads to lower the effective driving force of crack propagation, generating then a roughness-induced crack closure effect [13].

SEM observations of CT-BM fractured surface tested at $\mathrm{R}=0.1$ are presented in Fig. 12. It can be discernible that at $\Delta \mathrm{K}=10.5 \mathrm{MPa} \vee \mathrm{m}$, several secondary cracks are localized on a grain boundary resulting an intergranular propagation mode. At this stage, fractured surface presents high roughness and several cleavage facets. For $\Delta \mathrm{K}=15 \mathrm{MPa} \sqrt{\mathrm{m}}$, crack propagation mode is almost the same than CT-BM specimen tested at $\mathrm{R}=0.5$ at the same $\Delta \mathrm{K}$ value. SEM observation at $\Delta \mathrm{K}=33 \mathrm{MPa} \sqrt{\mathrm{m}}$ shows the presence of fatigue striations. Distance between striations was determined and it is equal to $7.1 \times 10^{-7} \mathrm{~m} /$ cycle, a value significantly higher to FCG rate at $\Delta \mathrm{K}=30 \mathrm{MPa} \sqrt{\mathrm{m}}$. It is important to note that FCG rate at $\Delta \mathrm{K}=33 \mathrm{MPa} \sqrt{\mathrm{m}}$ is not present in the da/dN- $\Delta \mathrm{K}$ curve, because of a disruption in the crack length measurement at this stage. As a conclusion, crack propagation mode of CT-BM specimens is not affected by load ratio and it depends on $\Delta K$ value. For lower $\Delta K$ values, crack propagation mode is influenced by microstructure, while for higher $\Delta \mathrm{K}$ value; crack propagation mode is transgranular with the presence of fatigue striations.

In order to explain the relationship between FCG behavior and microstructure, the reversible plastic zone (RPZ) size was determined for lower and higher $\Delta \mathrm{K}$ value in the stage II of crack propagation. The RPZ size $\left(r_{p}\right)$ under plane stress condition was defined as presented in Eq. 4 [14]:

$$
r_{p}=\left(\frac{1}{10 \pi}\right)\left(\frac{\Delta K}{\sigma_{0.2}}\right)^{2}
$$

Where $\Delta \mathrm{K}$ is the stress intensity factor range, and $\sigma_{0.2}$ is the yield strength. Rp values corresponding to different $\Delta \mathrm{K}$ values are summarized in Table 4.

At relatively low stress intensity factor range $(\Delta \mathrm{K}=11$ and $15 \mathrm{MPa} \sqrt{ } \mathrm{m})$, the reversible plastic zone (RPZ) size of Base Metal specimens is smaller than austenitic grain size, so the fatigue crack propagates by a mechanism that follows individual deformation mode of the localized area inside the grain and adjacent to the grain or twin boundaries [15]. At higher $\Delta \mathrm{K}$ value $(\Delta \mathrm{K}=20 \mathrm{MPa} \sqrt{\mathrm{m}})$, the RPZ size of Base Metal specimens is larger than the grain size, which enables the crack to interact with several grains during cyclic loading and to grow along grain boundaries, presenting a transgranular fracture mode [16]. Additionally, RPZ values in BM 
show that plastic zone size increases and exceeds grain size value when $\Delta \mathrm{K}$ reaches 20 $\mathrm{MPa} \sqrt{ } \mathrm{m}$, inducing then plasticity-induced crack closure at lower load ratio. In fact, at $\mathrm{R}=0.5$ crack closure are assumed to be limited, which is not the case at $\mathrm{R}=0.1$ [17]. Otherwise, Alloy28 Base Metal shows a high Bauschinger effect [18]. This can produce the contact between crack lips and causes crack closure. In addition, slip bands appearing on crack lips during cyclic loading can produce crack surface contact and contribute directly to crack closure phenomenon.

Referring to previous work, Trudel [19] showed that crack path deviations of a martensitic stainless steel reduce FCG at $\mathrm{R}=0.1$. In this work, it has been found that crack closure is induced by plasticity, roughness, oxide, viscous fluid and phase transformation [20]. Vor [21] highlighted the presence of crack closure by crack tip plasticity of a 304L austenitic stainless steel at low load ratio $(\mathrm{R}=0.1)$. In order to underline the effect of plasticity on crack closure, Pommier [22] showed that there is a relation between crack closure and cyclic behavior of a 316 austenitic stainless steel. This latter reveals an elevated Bauschinger effect which shows a high kinematic hardening. Pommier showed also that crack closure is directly linked to kinematic hardening in crack tip [22].

It can be considered that crack closure of CT-BM specimen is due to the roughness of crack surfaces as well as high plasticity in crack tip zone. As a conclusion, the difference between FCG rates of CT-BM specimens can be attributed to the roughness-induced and plasticityinduced crack closure phenomenon during the unloading process at $\mathrm{R}=0.1$.

\subsection{Fatigue Crack Growth tests on Alloy28 Weld Metal (CT-WM)}

\subsubsection{FCG tests results}

Fatigue Crack Growth tests were also performed on CT-WM specimen for the two load ratios: 0.1 and 0.5 . All results were revealed from binocular measurement, which limits the number of point in the da/dN- $\Delta \mathrm{K}$ curves. Fig. 13 summarizes the FCG behavior of the CT-WM specimens. It can be seen that FCG rate is significantly faster at $\mathrm{R}=0.5$ in the studied $\Delta \mathrm{K}$ range. For example, at $\Delta \mathrm{K}=20 \mathrm{MPa} \sqrt{\mathrm{m}}, \mathrm{FCG}$ rate is equal to $3.2 \times 10^{-8} \mathrm{~m} /$ cycle at $\mathrm{R}=0.5$ and to $10^{-8} \mathrm{~m} /$ cycle at $\mathrm{R}=0.1$. Table 5 shows the characteristic of $\mathrm{da} / \mathrm{dN}$ curves in the Paris domain. In order to understand the origin of this discard, fatigue crack propagation path and fracture surface observations of CT-WM specimens were performed. 


\subsubsection{Morphological analysis of CT-WM specimens}

In this section, only specimen tested at $\mathrm{R}=0.5$ is investigated. Fig. 14 shows SEM observations of the crack path of CT-WM specimen. It can be seen that crack path presents several deflections resulting a high tortuosity. In contrast, for lower $\Delta \mathrm{K}$ values, crack path is rectilinear, with an inclination of $45^{\circ}$ relative to the loading axis. From $\Delta \mathrm{K}=15 \mathrm{MPa} \sqrt{\mathrm{m}}$, crack path becomes more sinuous and many crack branching can be detectable. Beyond $\Delta \mathrm{K}=$ $30 \mathrm{MPa} \vee \mathrm{m}$, crack path exhibits a ductile zone which represents the final fatigue failure. SEM observation with high magnification of the zone corresponding to $\Delta \mathrm{K}=20 \mathrm{MPa} \sqrt{\mathrm{m}}(\mathrm{da} / \mathrm{dN}=$ $3 \times 10^{-8} \mathrm{~m} /$ cycle) is displayed in Fig. 15. It can be observed that crack path follows the weld metal grain orientation showing then a highly dependence on microstructure. As can be seen in the Weld Metal microstructure, dendritic grains are randomly oriented and depend to welding pass direction. Such a microstructure can change crack path each time it changes its orientation. During the process of fatigue crack growth, crack propagation was easily blocked and deflected when a fatigue crack encountered the grain boundaries because of the deviations in the micro-orientation of different grains.

These same results were found in the work of Jang et al. [23], focused on crack growth behavior of a welded 316L stainless steel. Authors have found that crack path is strongly dependent on microstructure and especially dendritic grain orientation. Jang et al. showed also that when the dendrite alignment is not favorable to the crack growth along the boundary, the crack grows across the boundary, resulting in a very wavy and tortuous crack path. When the crack changes its path, secondary cracks are frequently found. Trudel et al. have found the same results on a welded martensitic stainless steel [19]. Authors highlighted that crack growth path is largely driven by the weld's microstructural features, influencing the material resistance to fatigue crack growth. Singh et. al. have studied the fatigue crack growth on 168 OD pipe and they found that weld has better FCG resistance compared to the Heat Affected Zone [24]. The dendritic structure of the weld metal leads to directional effect and enhance fatigue crack growth resistance.

SEM observation of CT-WM fractured surface specimen tested at $\mathrm{R}=0.5$ are presented in Fig. 16. At $\Delta \mathrm{K}=11$ and $15 \mathrm{MPa} \sqrt{\mathrm{m}}$, fractured surface seems to have a roughly aspect with the presence of several secondary cracks. On the other hand, it can be observed the presence of brittle particles in the whole of fractured surface of the Alloy28 stainless steel as found in a previous work [18]. These particles are considered as welding defect which can produce a 
stress concentration zone. It can be found the presence of brittle particles in the zone corresponding to $\Delta \mathrm{K}=20 \mathrm{MPa} \sqrt{\mathrm{m}}$. Shang et al. have also found many welding inclusions in the fracture surface of $316 \mathrm{~L}$ weld specimen [25]. At $\Delta \mathrm{K}=30 \mathrm{MPa} \sqrt{\mathrm{m}}\left(\mathrm{da} / \mathrm{dN}=4 \times 10^{-7}\right.$ $\mathrm{m} /$ cycle) and $\Delta \mathrm{K}=40 \mathrm{MPa} \sqrt{\mathrm{m}}$, many ductile dimples are observed characterizing the high FCG rate zone. Concerning CT-WM specimen tested at $\mathrm{R}=0.1$, it is possible that deflection and crack branching are more pronounced, and reduce then the crack driving force slowing down the FCG rate. Hence, it plays an important role in enhancing the crack propagation resistance at $R=0.1$. As a conclusion, crack growth rate in Weld Metal specimens is affected by load ratio, and damage mechanisms are highly dependent on microstructure at different $\Delta \mathrm{K}$ value.

\subsection{Comparison of Crack Growth Rate between CT-BM and CT-WM specimens}

The Fatigue Crack Growth rate data for Base Metal and Weld Metal at $\mathrm{R}=0.1$ and 0.5 are summarized in Fig. 17. It can be observed that at $\mathrm{R}=0.1$, FCG rate of CT-BM and CT-WM is lower than tests at $\mathrm{R}=0.5$. This result is probably due to crack closure phenomenon which appears for tests performed at $\mathrm{R}=0.1$. As shown in Fig. 17, FCG behavior of CT-WM specimen is close to that of CT-BM specimen tested at $\mathrm{R}=0.5$. In contrast, da/dN- $\Delta \mathrm{K}$ curve of CT-WM at $\mathrm{R}=0.1$ is lower to that of CT-BM specimen and especially at high $\Delta \mathrm{K}$ values. This result can be explained by the high tortuosity of fatigue crack path of CT-WM specimen which enhances FCG resistance. Therefore, the combined effect of crack deflection, dendritic orientation and crack closure at $\mathrm{R}=0.1$ enhanced the crack growth resistance in CT-WM specimen more than in coarse-grained stainless steel such as CT-BM specimen. It was also deduced from previous work that welded zones present an important value of tensile or compression residual stresses [5]. In the case of this study, residual stresses were not been quantified. However, it can be supposed that residual stresses can be combined with other phenomena cited above and induce the contact between crack lips at $\mathrm{R}=0.1$, and then reduce FCG rate in the welded structure compared to $\mathrm{R}=0.5$.

Despite the high tortuosity of CT-WM crack path, FCG rate doesn't seems to be affected by this morphology and it is close to FCG rate of CT-BM at $\mathrm{R}=0.5$. Lieurade et al. indicated that generally fatigue resistance of most weld metals depends not only on mechanical properties, but also on internal defects in the structure [26]. Welding defects, as porosites between dendrites, microcracks and brittle particles formed after solidification, are considered as stress concentration zones which can increase FCG rate. In addition, as the crack closure 
phenomenon is absent in CT-WM specimen at $\mathrm{R}=0.5$, welding defects can accelerate crack growth rate and lead to decrease the FCG resistance and make it close to FCG behavior of CT-BM.

\subsection{Fatigue Crack Growth tests on Alloy28 welded joints}

\subsubsection{Crack Growth rate curves}

Fatigue Crack Growth tests were performed on CT-WJ specimen notched perpendicularly to welded joint as shown in Fig. $3 \mathrm{c}$ ). The test was carried out at constant $\Delta \mathrm{K}=20 \mathrm{MPa} \sqrt{\mathrm{m}}$ and at $\mathrm{R}=0.1$. Crack propagates initially in the Base Metal in the rolling direction, and then reaches Weld Metal zone. This test enables to determine FCG rate evolution when crack reaches Weld Metal. The cycle counter was initialized to zero when crack begins to propagate in Weld Metal. Crack length evolution versus number of cycles curve as well as FCG rate versus crack length in Base Metal and Weld Metal zone can then be determined (Fig. 18 and Fig. 19 respectively). Crack length evolution presents a linear law with a slope equal to $4 \times 10^{-6}$ $\mathrm{mm} /$ cycle and $3 \times 10^{-6} \mathrm{~mm} /$ cycle for Base Metal and Weld Metal zone respectively. Although the microstructure of Weld Metal is mainly constituted of hard dendritic grains, which limits the size of plastic zone at crack tip as showed in table 5, FCG rate is almost close to the one of Base Metal zone, with a slight decrease. This can be explained by the presence of different phenomenon such as welding defects and residual stresses which can be compensated and balanced that leads to have a similar FCG rate in Weld Metal and Base Metal zone. In order to understand this behavior, SEM observation of fractured CT-WJ specimen is necessary.

\subsubsection{Morphological analysis of CTWJ specimens}

Optical micrograph of crack path of Weld Metal specimen is showed in Fig. 20. It can be seen that crack path is more tortuous when crack reaches Weld Metal zone. It can be noted also that dendritic orientation is perpendicular to crack propagation axis, giving then a cellular shape contrarily to CT-WM specimens. The fatigue crack path deflection of CT-WM is more pronounced than CT-WJ specimen. The difference of crack path morphology and of microstructure orientation can induce a slight increase of FCG rate in Weld Metal zone compared to CT-WM specimen $\left(3 \times 10^{-8} \mathrm{~m} /\right.$ cycle and $10^{-8} \mathrm{~m} /$ cycle respectively). The optical micrograph of fractured surface of CT-WJ specimen is displayed in Fig. 21. It can be seen that there is a difference between surface morphology of Base Metal zone and Weld Metal zone with a rougher aspect in the Base Metal zone. SEM observations of the different zone of 
CT-WJ specimen were carried out and showed in Fig. 22. It can be observed that Base Metal presents a high roughness surface compared to Weld Metal. The stability of FCG rate between the two studied zones can be explained by the presence of multiple phenomena, as roughnessinduced crack closure in Base Metal which decelerates FCG rate, and also the presence of brittle particles combined to residual stress in Weld Metal which can accelerate FCG rate. These phenomena can be balanced producing a slight variation of FCG rate between Base Metal and Weld Metal zones in CT-WJ specimen.

\subsection{Conclusions}

The Fatigue Crack Growth behavior of SMAW welded Alloy28 superaustenitic stainless steel is investigated in this study. The main conclusions are drawn as follows:

(1) Fatigue Crack Growth rate is affected by load ratio for Base Metal and Weld Metal specimens. This result is due to the presence of roughness-induced and plasticity-induced crack closure at lower load ratio.

(2) Base Metal specimens present a crack propagation mode influenced by microstructure for lower $\Delta \mathrm{K}$ values, while for higher $\Delta \mathrm{K}$, crack propagation mode is transgranular with the presence of fatigue striations.

(3) Damage mechanisms of Weld Metal specimens are highly dependent to microstructure at different $\Delta \mathrm{K}$ value.

(4) Based on microstructural observation of fatigue crack growth path of Weld Metal specimen, it is found that crack follows dendritic orientation giving then a tortuous crack path which enhances Fatigue Crack Growth resistance at $\mathrm{R}=0.1$.

(5) It can be supposed that different phenomena can be compensated in CT-WM specimen, such as plasticity, welding defects, residual stresses, tortuosity and roughness, and lead FCG behavior similar to CT-BM specimens at $\mathrm{R}=0.5$. Concerning CT-WJ specimen, it presents an almost stable Fatigue Crack Growth rate between Base Metal and Weld Metal zones which can be attributed to combination of crack deflection, roughness-induced crack closure, plasticity-induced crack closure, welding defects and residual stresses. 


\section{References}

[1] Punit Arora, Saroj Kumar, P.K. Singh, V. Bhasin, R.K. Singh, K.K. Vaze. Fatigue Crack Growth Studies on Narrow Gap Pipe Welds of Austenitic Stainless Steel Material. Procedia Engineering, Volume 86, 2014, Pages 203-208.

[2] Rao EJ, Guha B, Malakondaiah G, Radhakrishnan VM. Effects of welding process on fatigue crack growth behaviour of austenitic stainless steel welds in a low alloy (Q\&T) steel. Theor Appl Fract Mech, 27, 1997, Pages 141-8.

[3] Tsay LW, Tasy CY. The effect of microstructures on the fatigue crack growth in Ti-6Al4V laser welds. Int J Fatigue, 19, 1997, Pages 713.

[4] Changheui Jang, Pyung-Yeon Cho, Minu Kim, Seung-Jin Oh, Jun-Seog Yang. Effects of microstructure and residual stress on fatigue crack growth of stainless steel narrow gap welds. Materials and Design, 31, 2010, Pages 1862-1870.

[5] Masao Itatani, Juichi Fukakura, Masayuki Asano, Masaaki Kikuchi, Noriyuki Chujo. Fatigue crack growth behavior of weld heat-affected zone of type 304 stainless steel in high temperature water. Nuclear Engineering and Design, 153, 1994, Pages 27-34.

[6] Shengci Li, Yonglin Kang, Guoming Zhu, Shuang Kuang. Microstructure and fatigue crack growth behavior in tungsten inert gas welded DP780 dual-phase steel. Materials and Design 85 (2015) 180-189.

[7] Xionglin Deng, Fenggui Lu, Haichao Cui, Xinhua Tang, Zhuguo Li. Microstructure correlation and fatigue crack growth behavior in dissimilar $9 \mathrm{Cr} / \mathrm{CrMoV}$ welded joint. Materials Science and Engineering: A. Volume 651, 10 January 2016, Pages 1018-1030.

[8] J.T. Al-Haidary, A.A. WAHAB, and E.H. ABDUL SALAM. Fatigue Crack Propagation in Austenitic Stainless Steel Weldments. Metallurgical and Materials Transactions A. Volume 37a, November 2006, 3206.

[9] V. Chaswal, G. Sasikala, S. Ray, S. Mannan, B. Raj. Fatigue crack growth mechanism in aged 9Cr-1Mo steel: threshold and Paris regimes. Materials Science and Engineering: A. Volume 395, Issues 1-2, 25 March 2005, Pages 251-264.

[10] P. Paris, F. Erdogan, J. Fluids Eng. 85 (1963) 528-533.

[11] ASTM International. Standard Test Method for Measurement of Fatigue Crack Growth Rates. ASTM International. United States, 2011.

[12] S. Kwofie. Equivalent stress approach to predicting the effect of stress ratio on fatigue threshold stress intensity range. International Journal of Fatigue. Volume 26, Issue 3, March 2004, Pages 299-303. 
[13] R.O. Ritchie, S. Suresh. Some considerations on fatigue crack closure at near-threshold stress intensities due to fracture surface morphology. Metallurgical Transactions A 13 (1982) 937-940.

[14] B. Budianski, J.W. Huchinson. J. Appl. Mech. Trans. ASME 45 (1978) 267-276.

[15] M. Goto, S.Z. Han, K. Euh. Formation of a high-cycle fatigue fracture surface and a crack growth mechanism of ultrafine-grained copper with different stages of microstructural evolution. Acta Materialia. Volume 58, Issue 19, November 2010, Pages 6294-6305.

[16] Ho-Kyung Kim, Myung-Il Choi, Chin-Sung Chung, Dong Hyuk Shin. Fatigue properties of ultrafine grained low carbon steel produced by equal channel angular pressing. Materials Science and Engineering A340 (2003) 243-250.

[17] Y. Xiong, C.Z. Shao, H.Y. Zheng. Fatigue crack growth behavior in fusion zone of 16MnR steel weldment. Adv. Mater. Res. 97 (101) (2010) 699-702.

[18] Y. Kchaou, N. Haddar, G. Hénaff, V. Pelosin, K. Elleuch. Microstructural, compositional and mechanical investigation of Shielded Metal Arc Welding (SMAW) welded superaustenitic UNS N08028 (Alloy28) stainless steel. Mater. Des. 63 (2014) 278-285.

[19] Alexandre Trudel, Michel Sabourin, Martin Lévesque, Myriam Brochu. Fatigue crack growth in the heat affected zone of a hydraulic turbine runner weld. International Journal of Fatigue. 66, 2014, Pages 39-46.

[20] J.C. Newman, Jr. and Wolf Elber. Mechanics of fatigue crack closure. ASTM 1916 Race Street Philadelphia, PA 19103.

[21] Kokleang Vor. Etude expérimentale et modélisation numérique de la fermeture de fissures longues et courtes dans un acier inoxydable 304L. Thèse de doctorat. Ecole Nationale Supérieure de Mécanique et d'Aérotechnique. 2009.

[22] Pommier S. Plane strain crack closure and cyclic hardening. Engineering Fracture Mechanics, 69, 2002, Pages 25-44.

[23] Changheui Jang, Pyung-Yeon Cho, Minu Kim, Seung-Jin Oh, Jun-Seog Yang. Effects of microstructure and residual stress on fatigue crack growth of stainless steel narrow gap welds. Materials and Design. 31, 2010, Pages 1862-1870.

[24] P.K.Singh, V.Bhasin, K.K.Vaze, A.K.Ghosh. Fatigue Studies on Austenitic Stainless Steel Pipe Weld. International Congress 2008, International Institute of welding, Chennai.

[25] Yi-Bo Shang, Hui-Ji Shi, Zhao-Xi Wang, Guo-Dong Zhang. In-situ SEM study of short fatigue crack propagation behavior in a dissimilar metal welded joint of nuclear power plant. Materials and Design. 88 (2015) 598-609.

[26] H.P. Lieurade. Welding World. vol. 21, 11, 1983, Pages 272-94. 


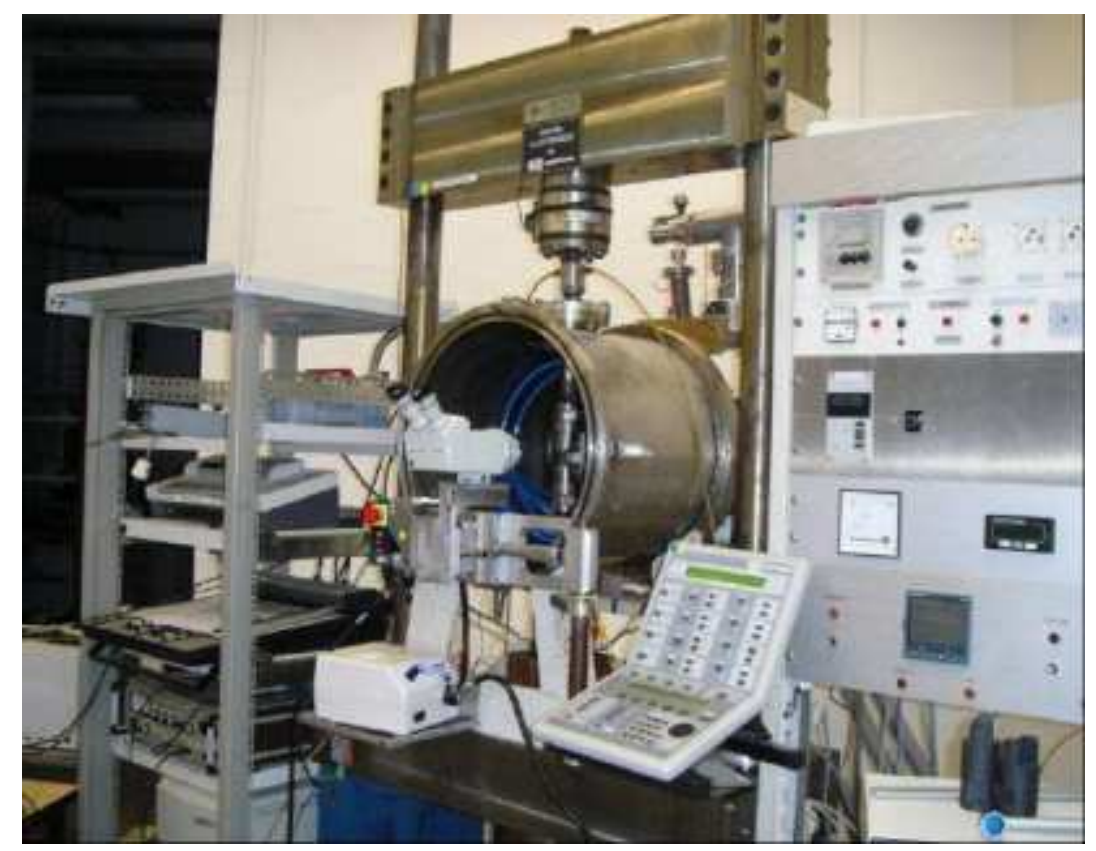

Figure 1. Fatigue crack growth test machine
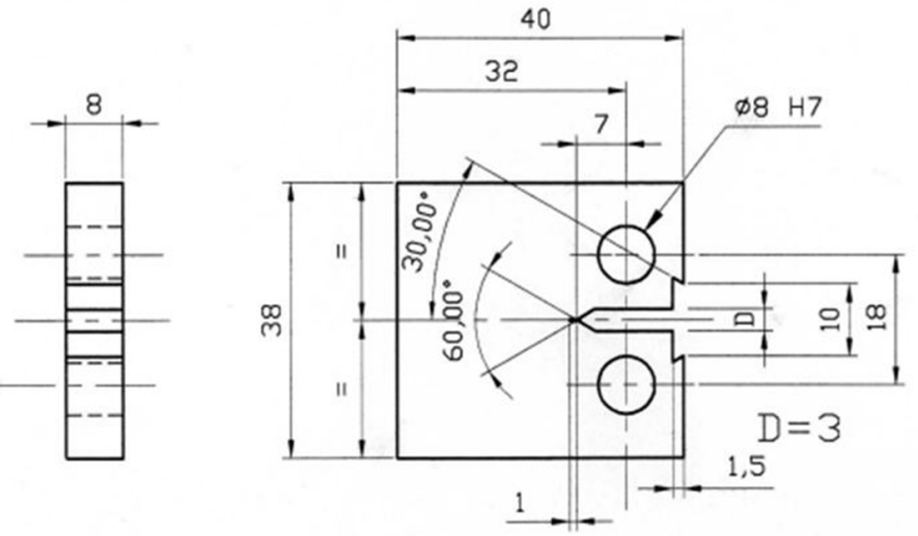

Figure 2. Specimen's detail

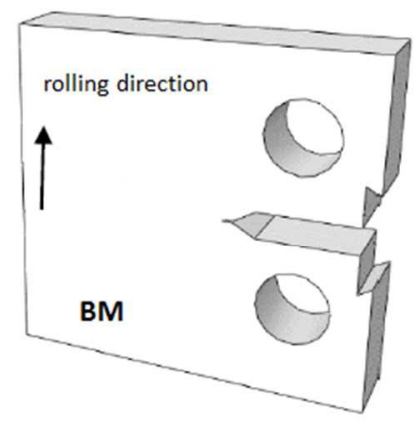

(a)

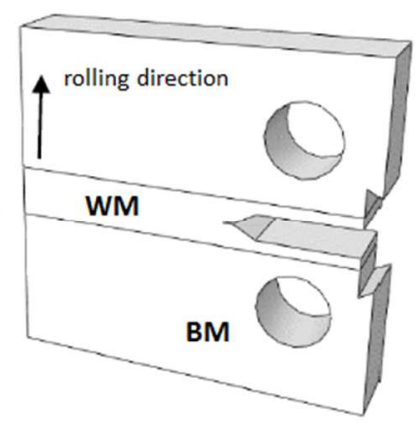

(b)

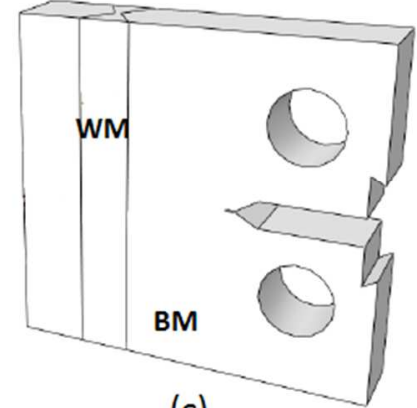

(c)

Figure 3. CT Specimen configuration, a) Base Metal ; b) Weld Metal ; c) Welded Joint 


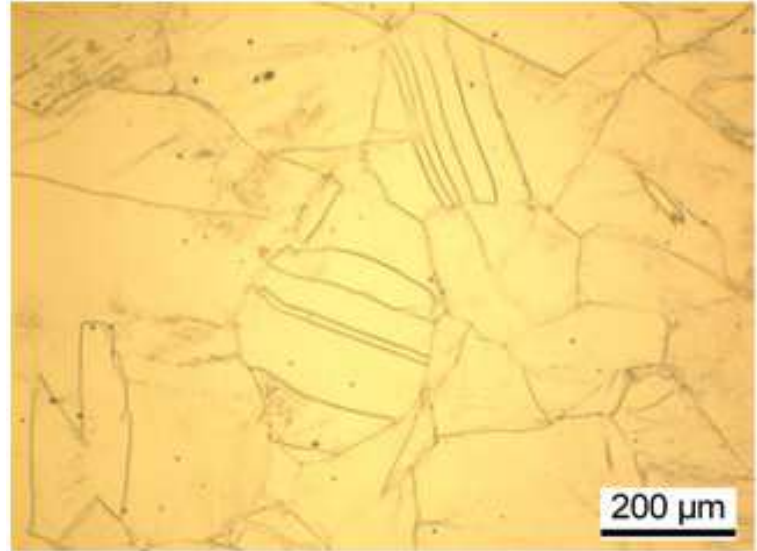

(a)

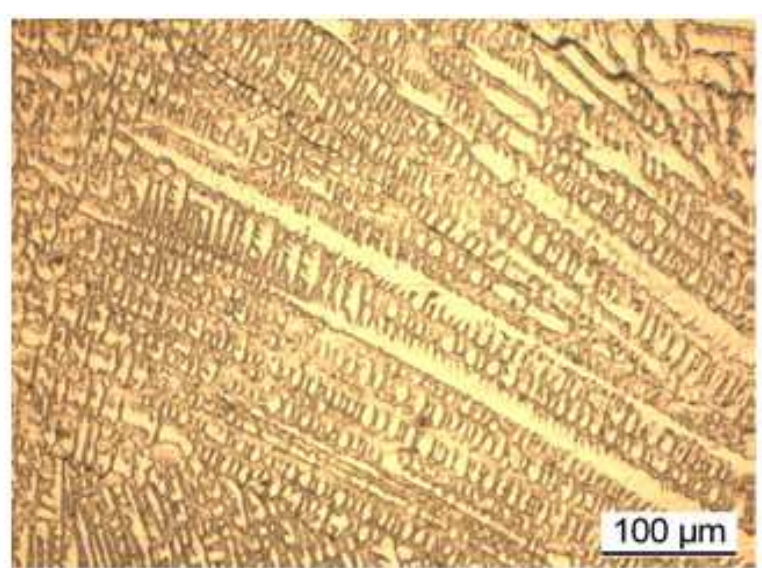

(b)

Figure 4. Optical micrographs of a) Base Metal; b) Weld Metal
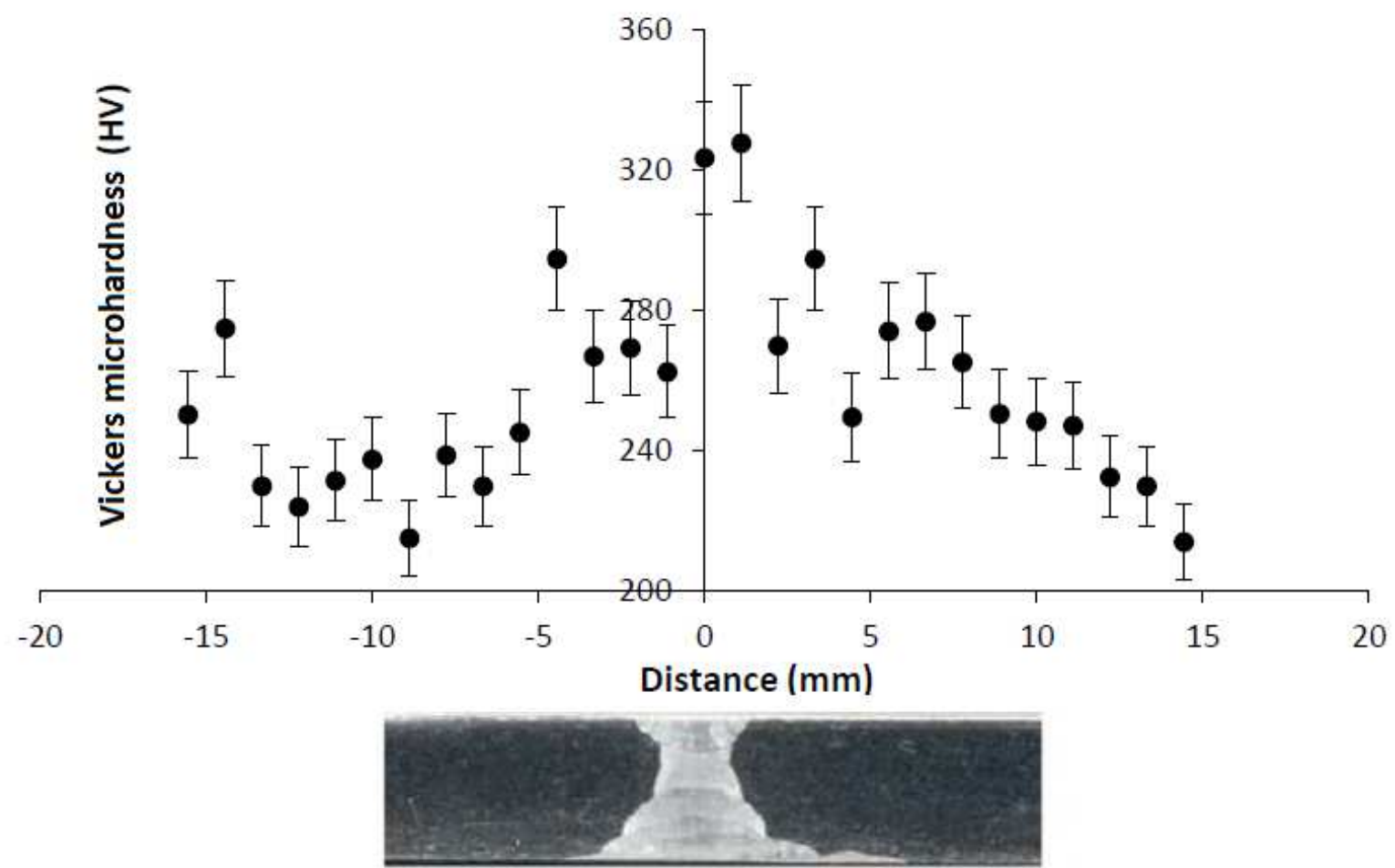

Figure 5. Microhardness profile 


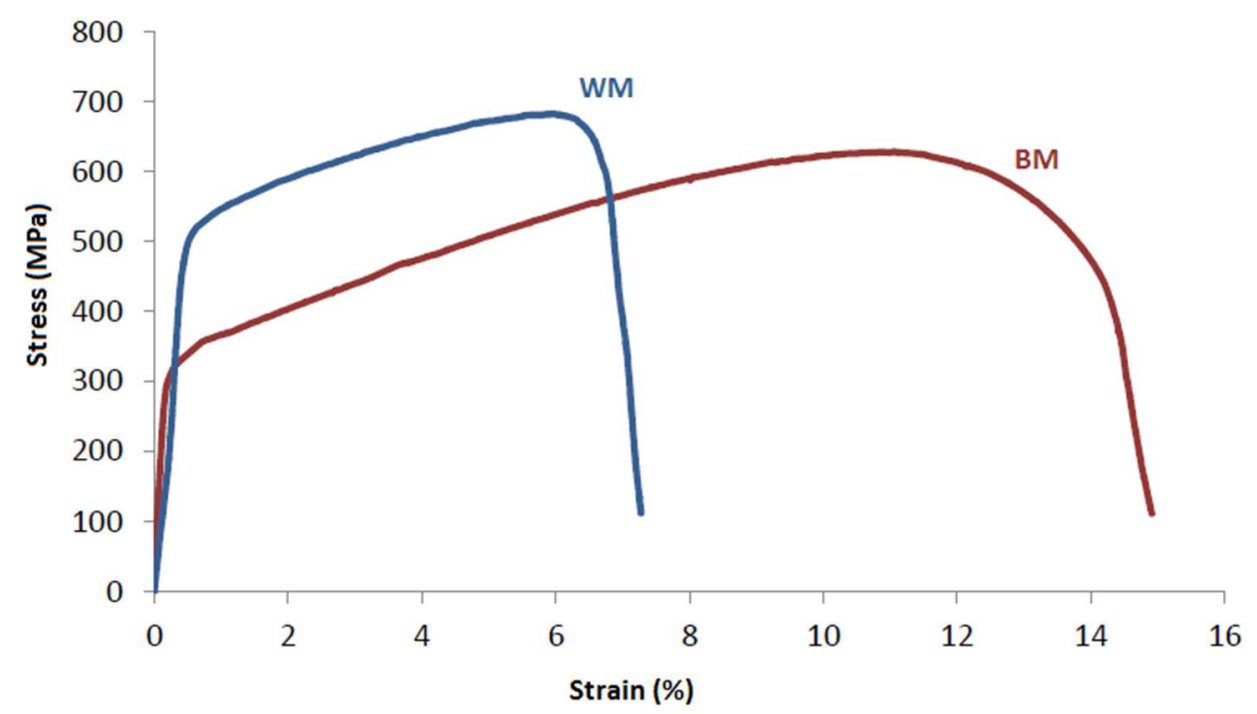

Figure 6. Stress-strain curve of BM and WM specimens

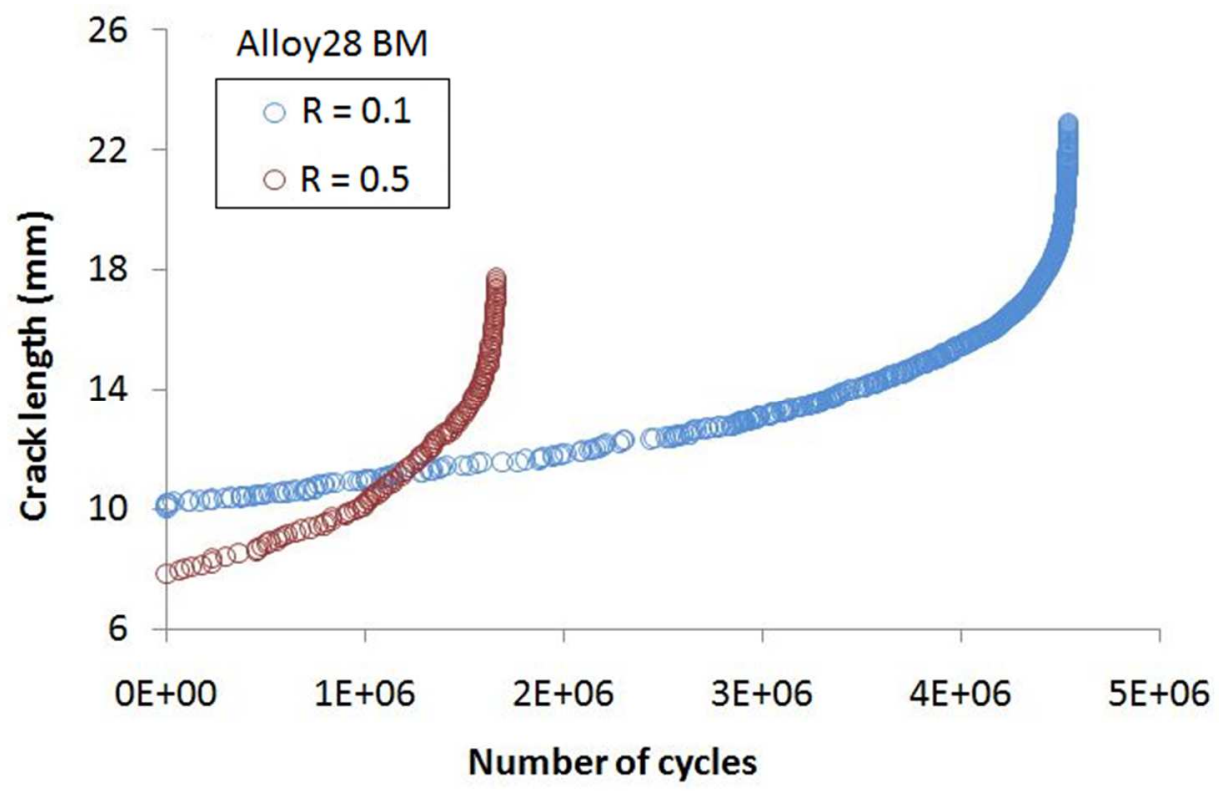

Figure 7. Base Metal - Crack length evolution against number of cycles 


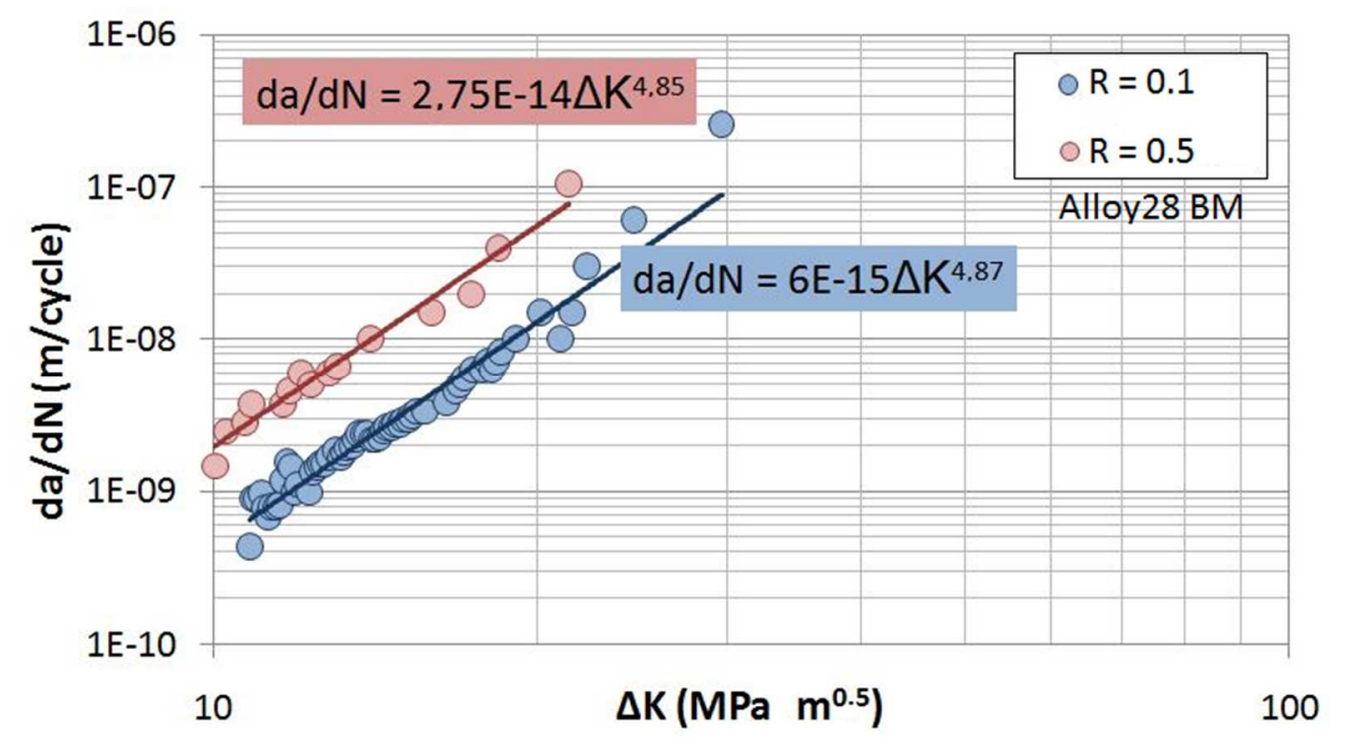

Figure 8. Base Metal - Crack growth rate evolution versus $\Delta \mathrm{K}$ 

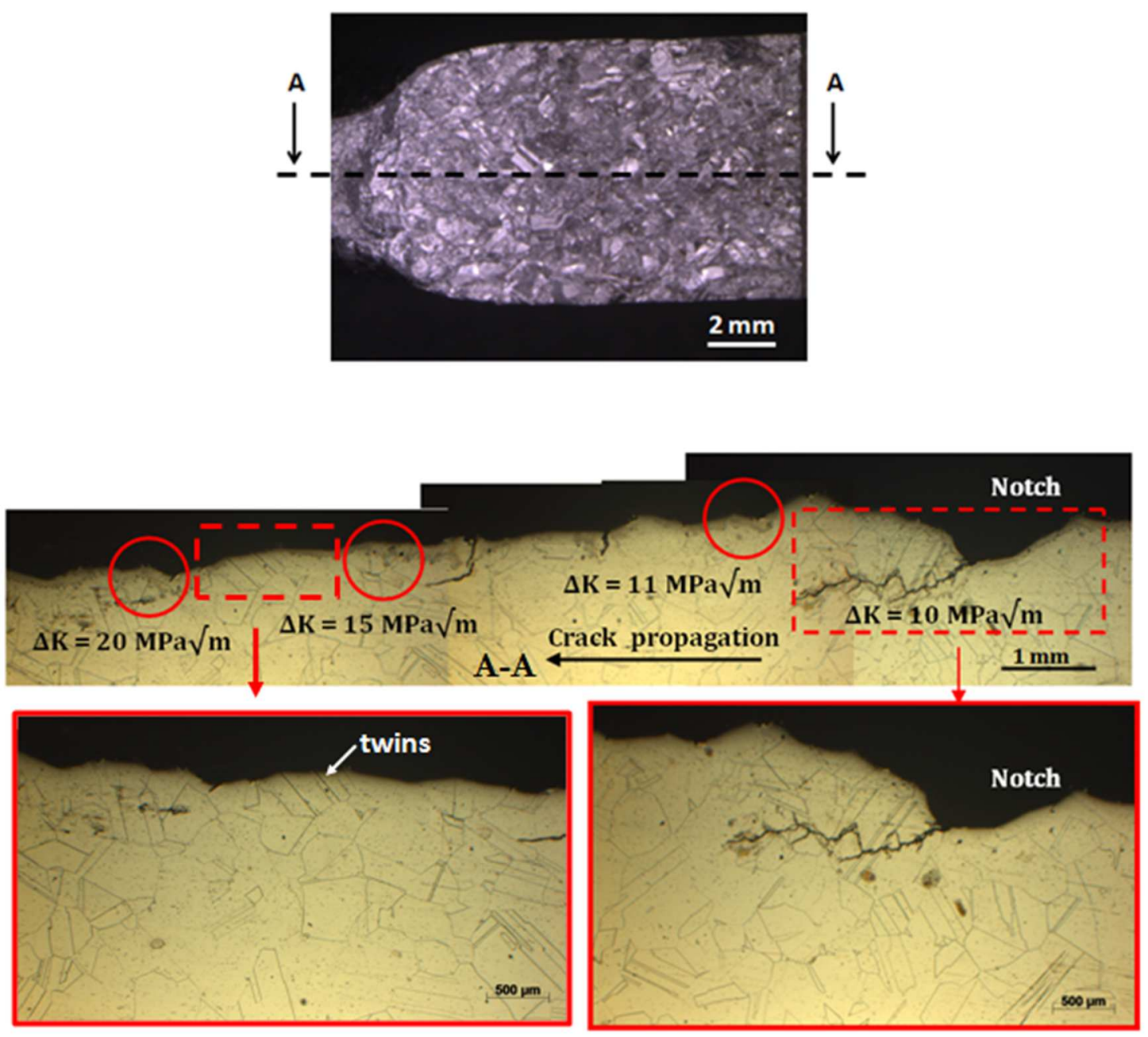

Figure 9. Crack path of CT-BM specimen, $\mathrm{R}=0.5$ 


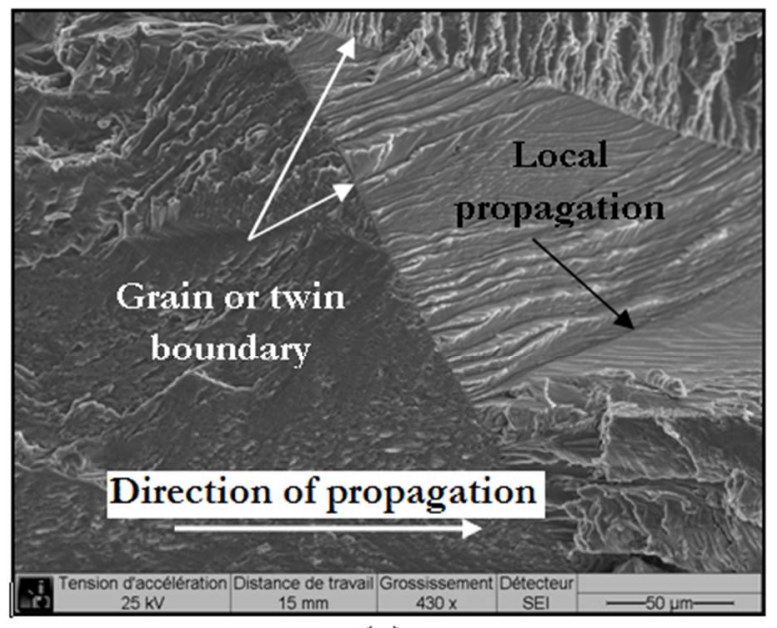

(a)

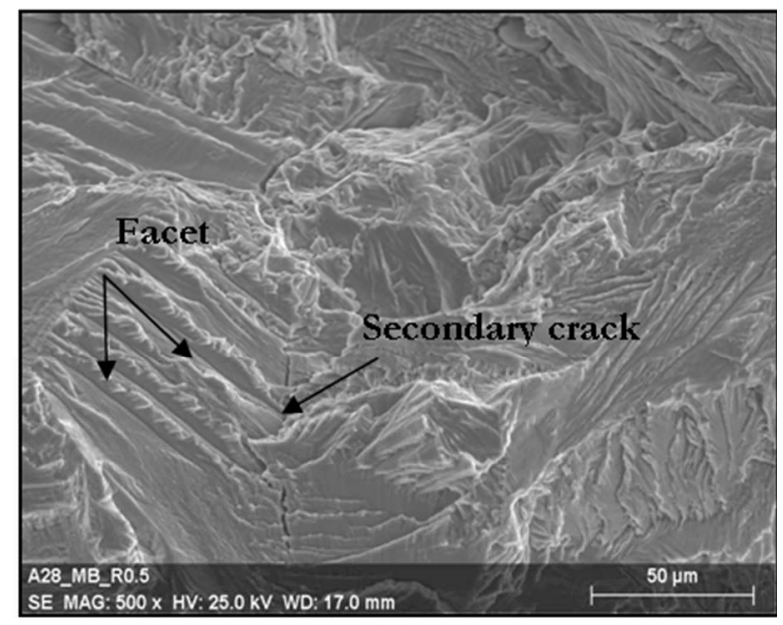

(b)

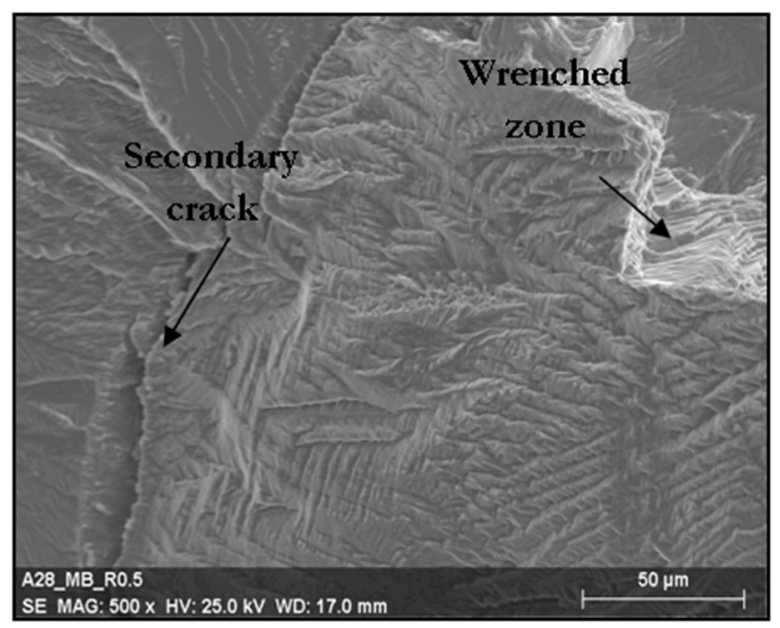

(c)

Figure 10. CT-BM specimen - R = 0.5 - SEM observations of fractured surface for different $\Delta \mathrm{K}$; a) $\Delta \mathrm{K}=11 \mathrm{MPa} \sqrt{\mathrm{m}}\left(\mathrm{da} / \mathrm{dN}=4 \times 10^{-9} \mathrm{~m} /\right.$ cycle $\left.) ; \mathrm{b}\right) \Delta \mathrm{K}=15 \mathrm{MPa} \sqrt{\mathrm{m}}\left(\mathrm{da} / \mathrm{dN}=1.3 \times 10^{-8}\right.$ $\mathrm{m} /$ cycle $) ; \mathrm{c}) \Delta \mathrm{K}=20 \mathrm{MPa} \sqrt{\mathrm{m}}\left(\mathrm{da} / \mathrm{dN}=6 \times 10^{-8} \mathrm{~m} /\right.$ cycle $)$ 

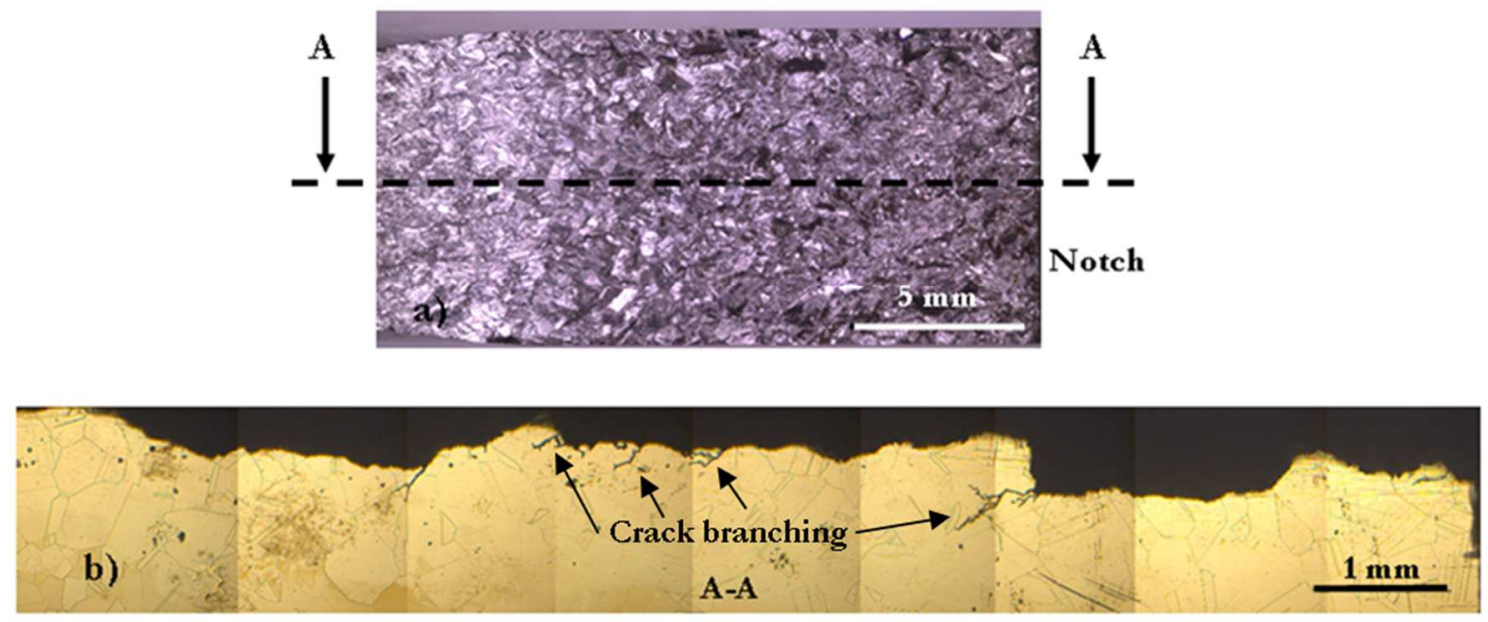

Figure 11. CT-BM specimen - $\mathrm{R}=0.1$; a) Optical micrograph of fractured surface; b) Crack path 


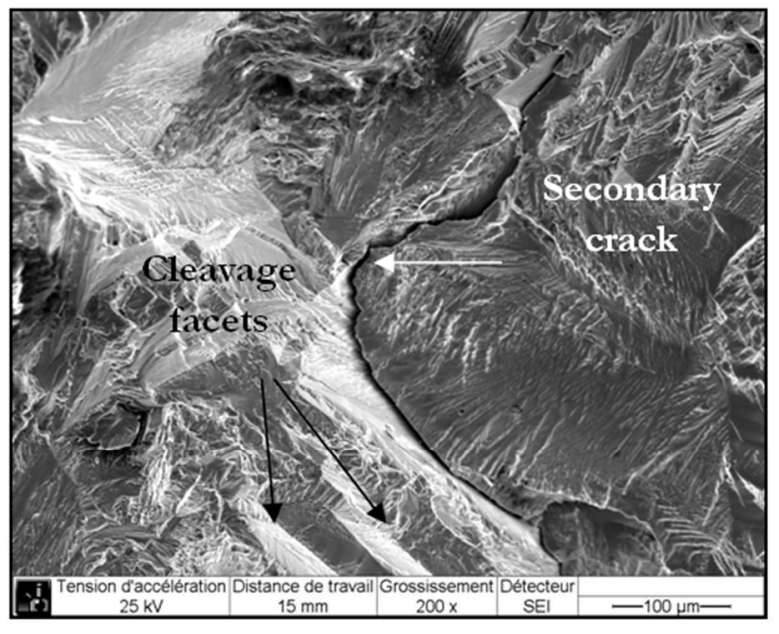

(a)

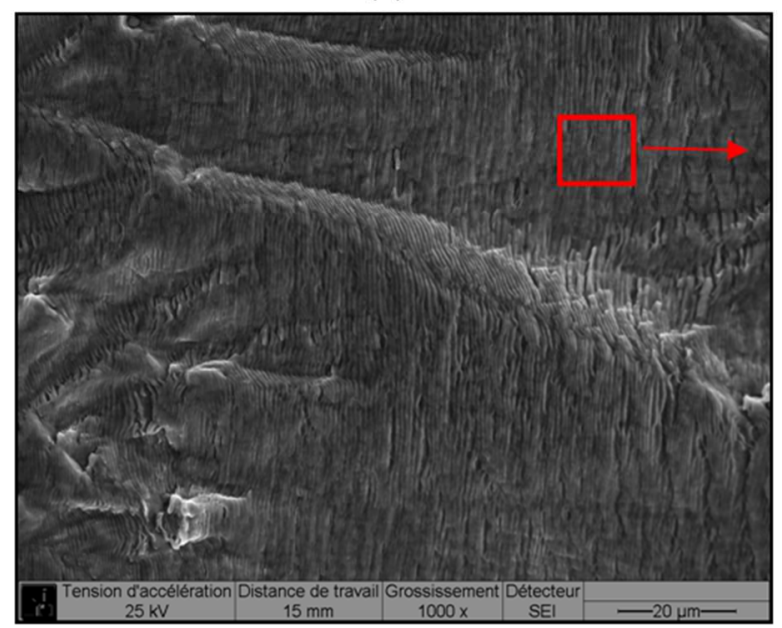

(c)

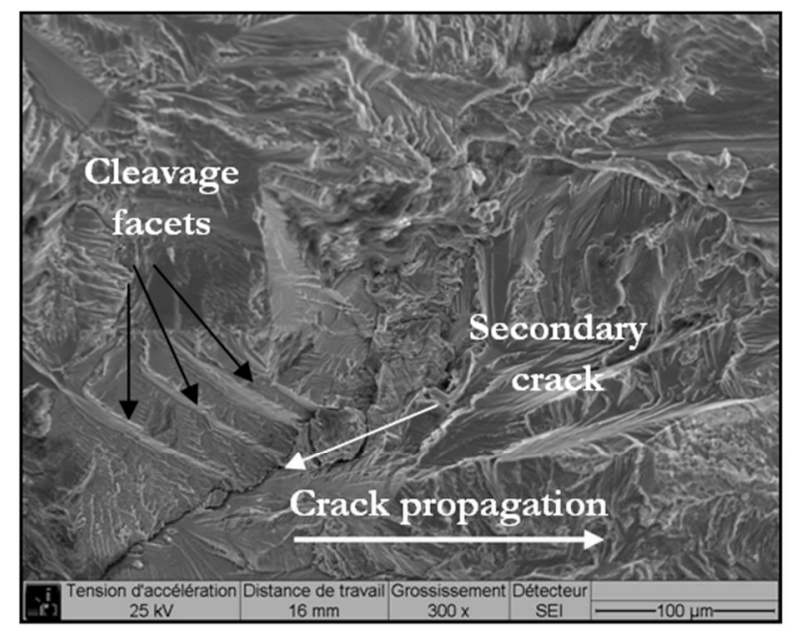

(b)

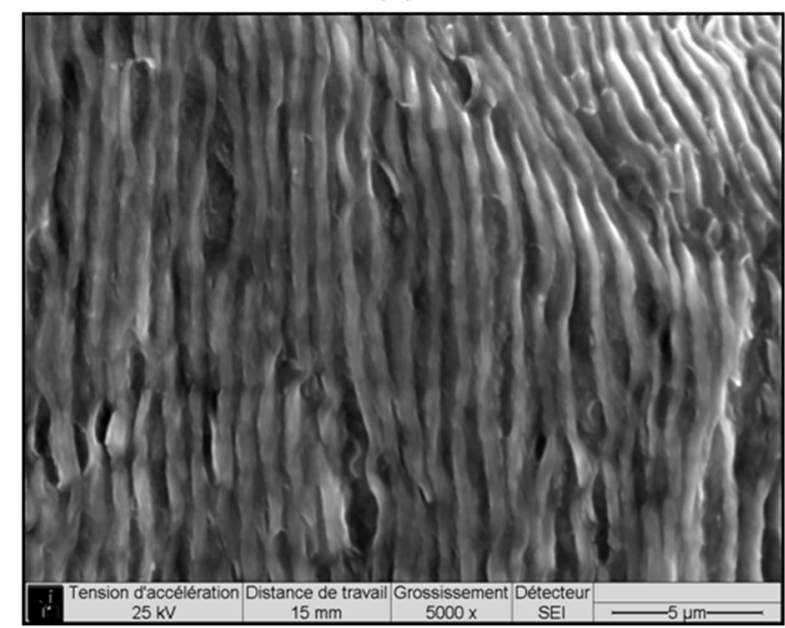

(d)

Figure 12. CT-BM specimen - $\mathrm{R}=0.1$ - SEM observations of fractured surface for different $\Delta \mathrm{K}$; a) $\Delta \mathrm{K}=10,5 \mathrm{MPa} \sqrt{\mathrm{m}}$; b) $\Delta \mathrm{K}=15 \mathrm{MPa} \sqrt{\mathrm{m}}$; c) $\Delta \mathrm{K}=33 \mathrm{MPa} \sqrt{\mathrm{m}}$; d) zoom of c) 


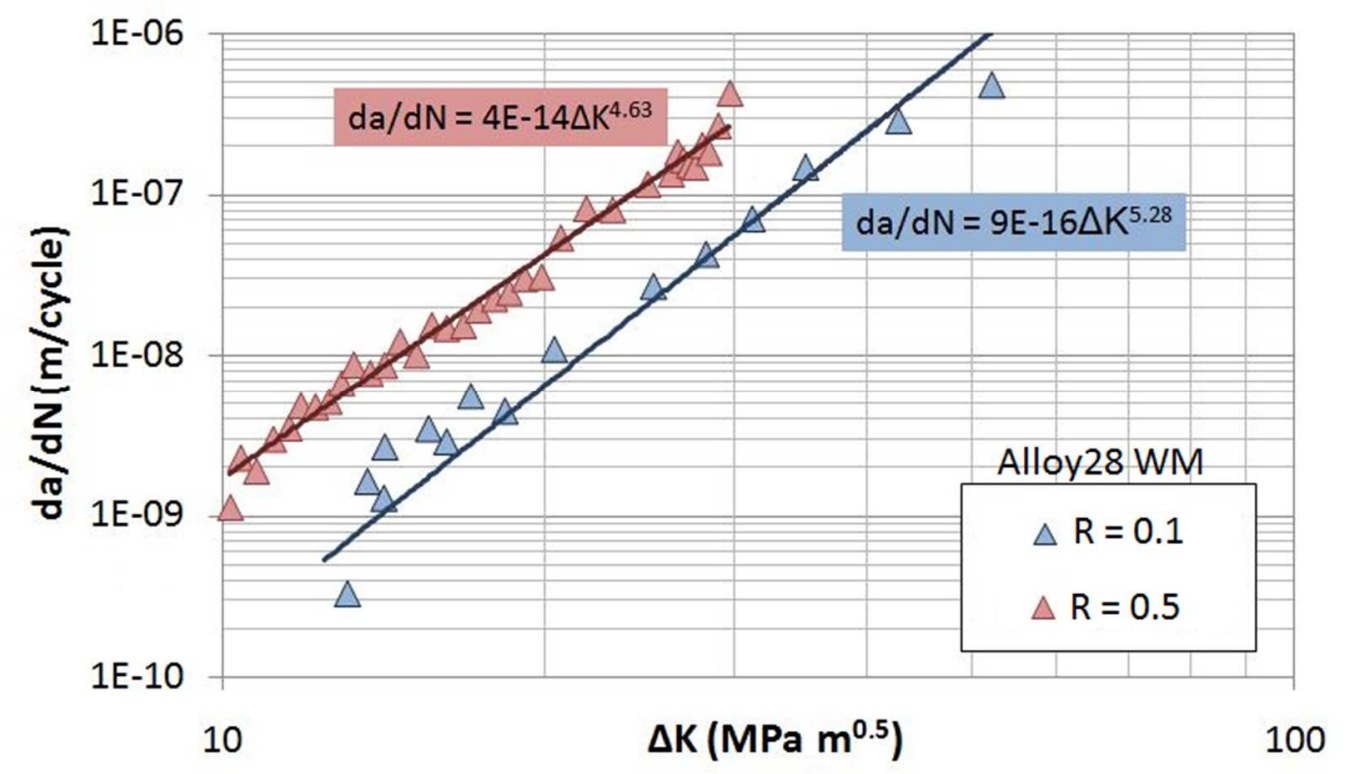

Figure 13. CT-WM specimens - Crack growth rate evolution versus $\Delta \mathrm{K}$
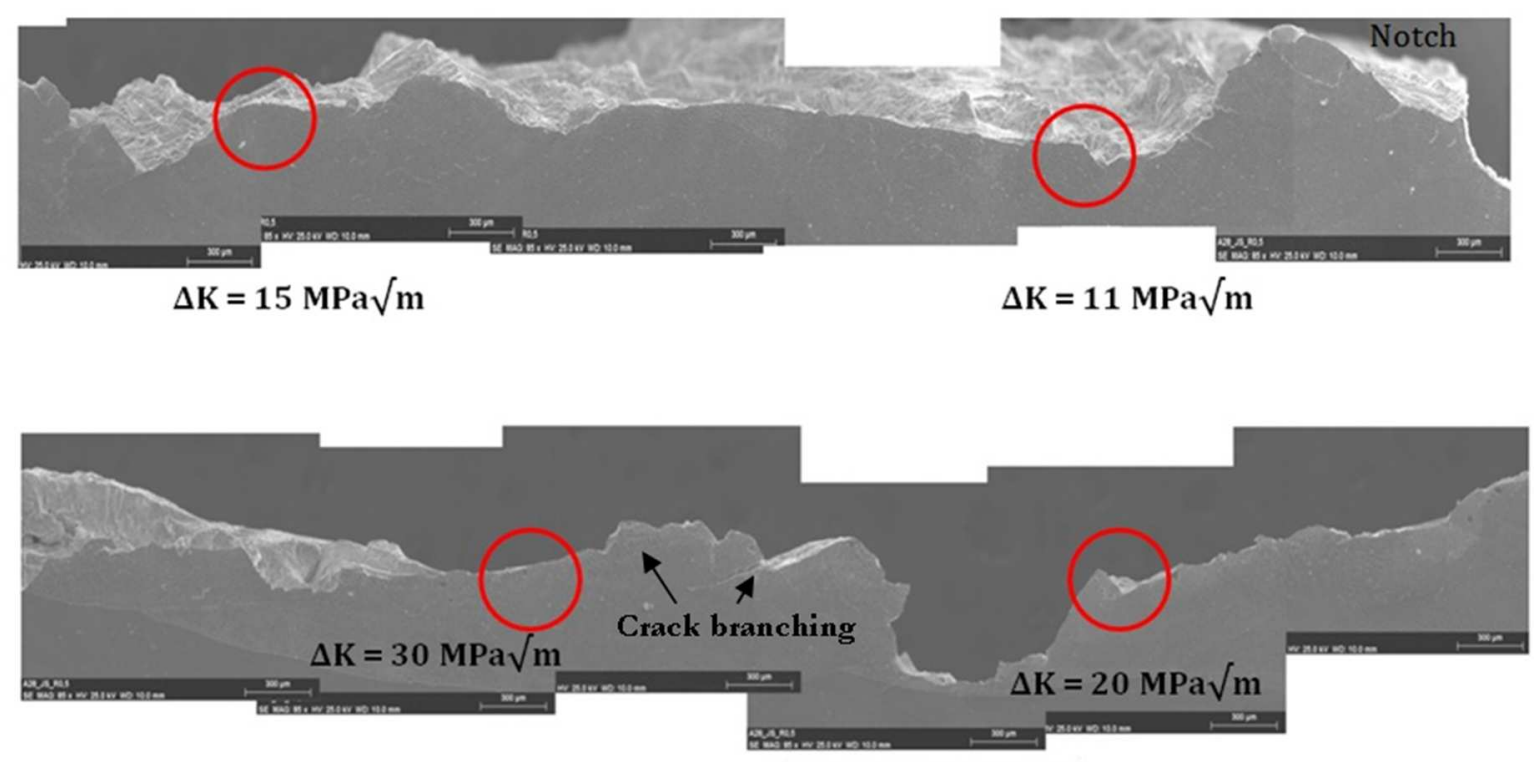

Figure 14. CT-WM specimen - R = 0.5 - Crack path details 

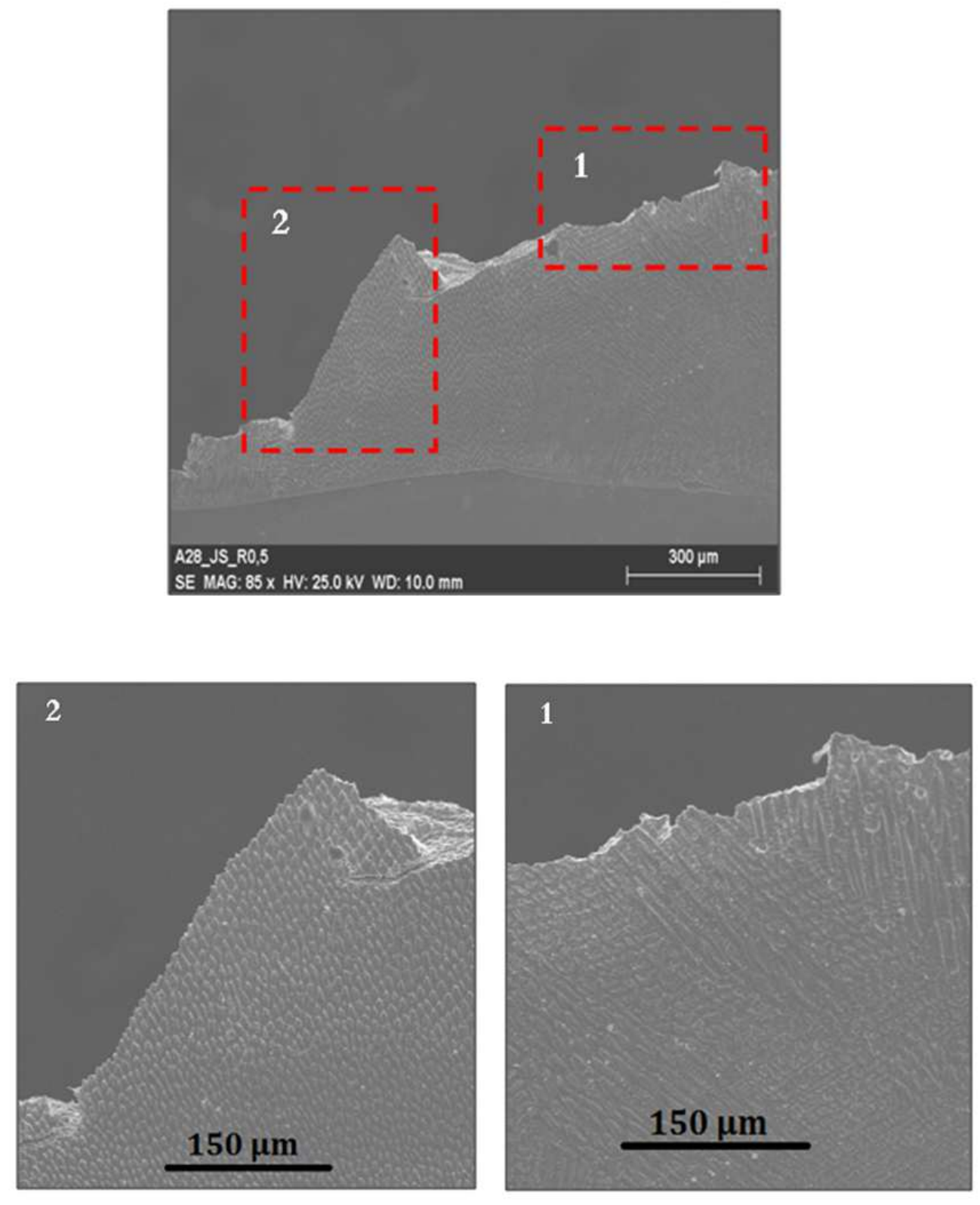

Figure 15. CT-WM specimen - Zoom of crack path at $\Delta \mathrm{K}=20 \mathrm{MPa} \sqrt{\mathrm{m}}$ 


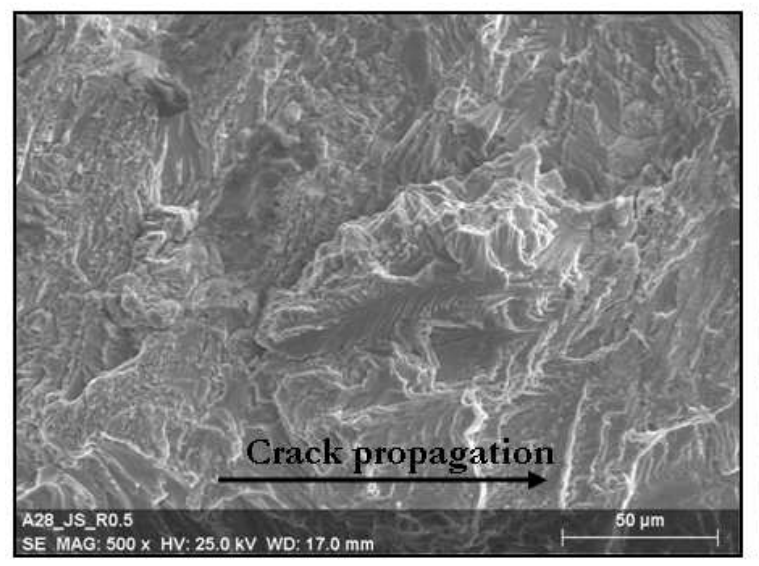

(a)

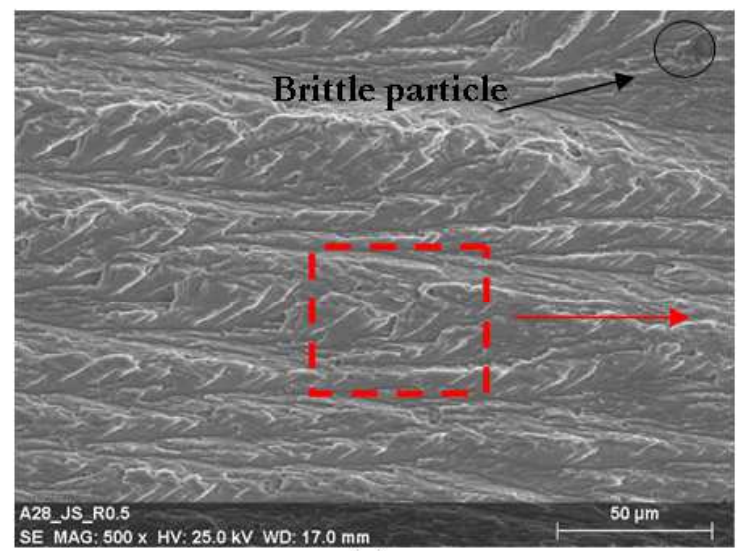

(c)

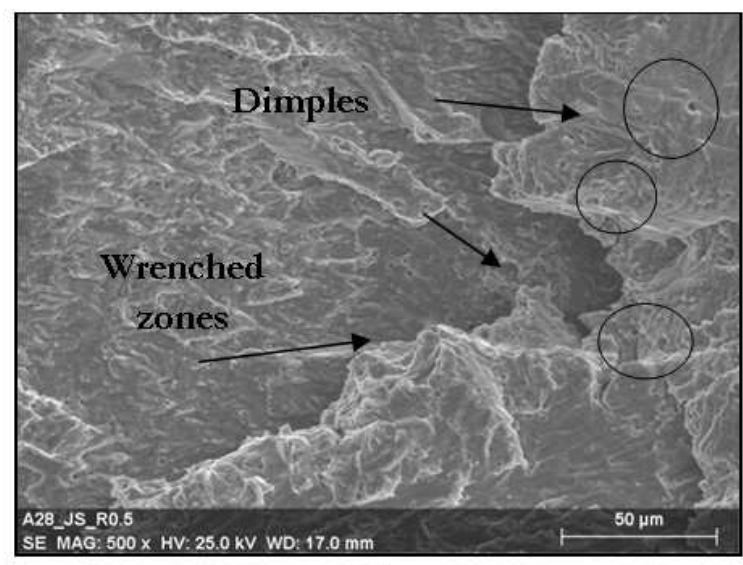

(e)

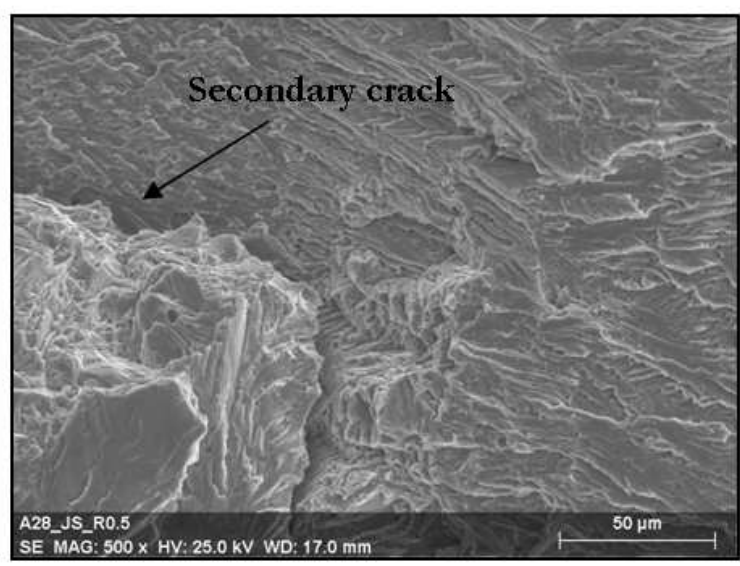

(b)

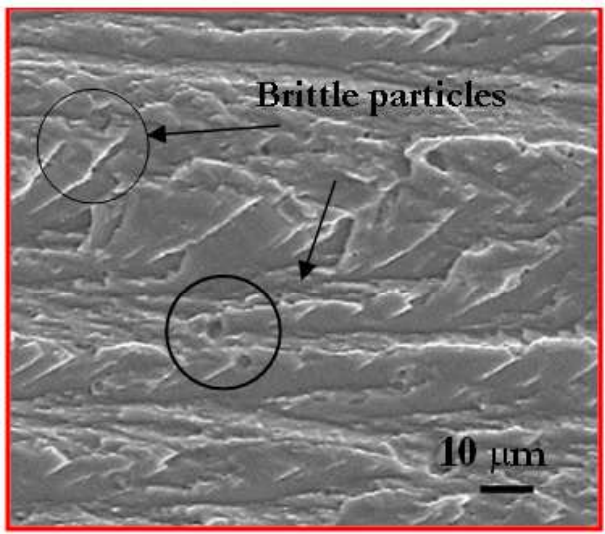

(d)

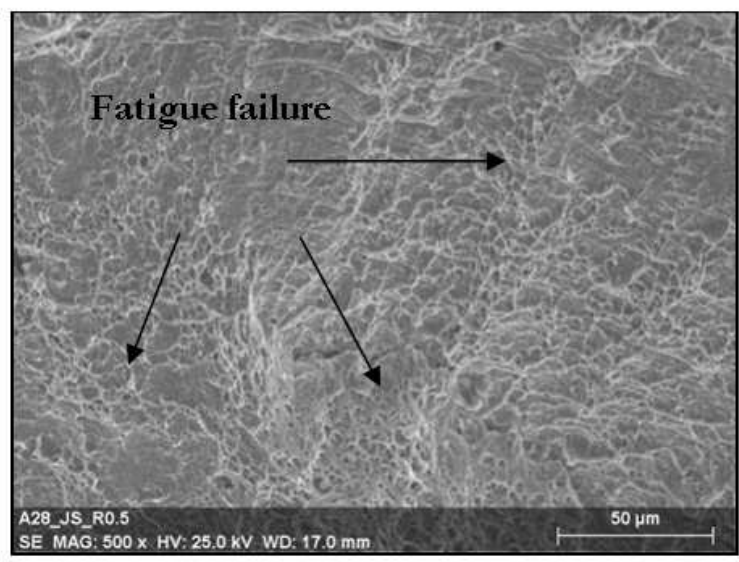

(f)

Figure 16. CT-WM specimen - $\mathrm{R}=0.5$ - SEM observations of fractured surface for different $\Delta \mathrm{K}$; a) $\Delta \mathrm{K}=11 \mathrm{MPa} \sqrt{\mathrm{m}}\left(\mathrm{da} / \mathrm{dN}=3 \times 10^{-9} \mathrm{~m} /\right.$ cycle $)$; b) $\Delta \mathrm{K}=15 \mathrm{MPa} \sqrt{\mathrm{m}}\left(\mathrm{da} / \mathrm{dN}=8 \times 10^{-9}\right.$ /cycle) ; c) $\Delta \mathrm{K}=20 \mathrm{MPa} \sqrt{\mathrm{m}}\left(\mathrm{da} / \mathrm{dN}=10^{-8} \mathrm{~m} /\right.$ cycle $)$; d) Zoom of $\Delta \mathrm{K}=20 \mathrm{MPa} \sqrt{\mathrm{m}}$; e) $\Delta \mathrm{K}=$ $30 \mathrm{MPa} \sqrt{\mathrm{m}}\left(\mathrm{da} / \mathrm{dN}=4 \times 10^{-7} /\right.$ cycle $\left.) ; \mathrm{f}\right) \Delta \mathrm{K}=40 \mathrm{MPa} \sqrt{\mathrm{m}}$ 


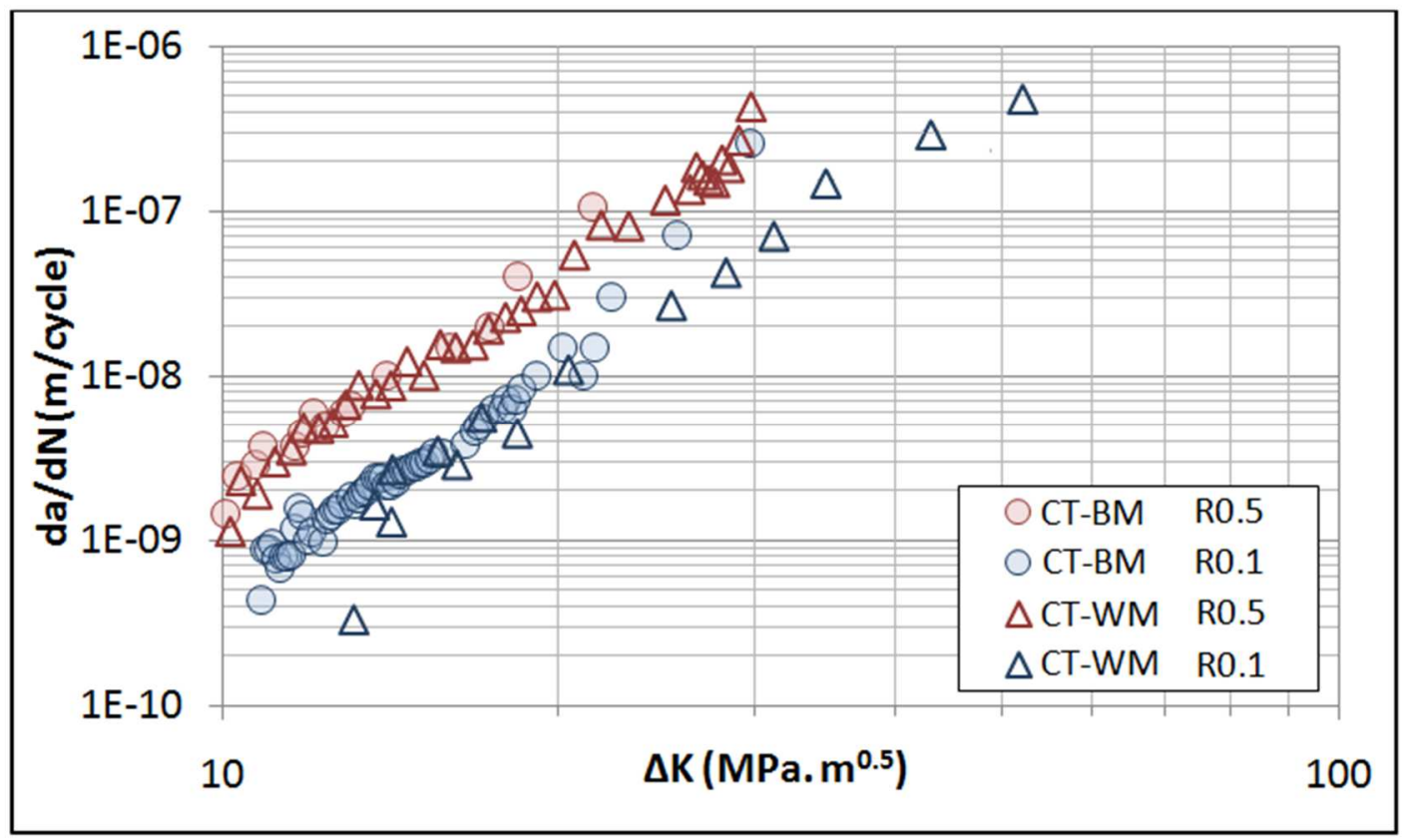

Figure 17. Comparison of crack growth rate evolution between CT-BM and CT-WM specimens

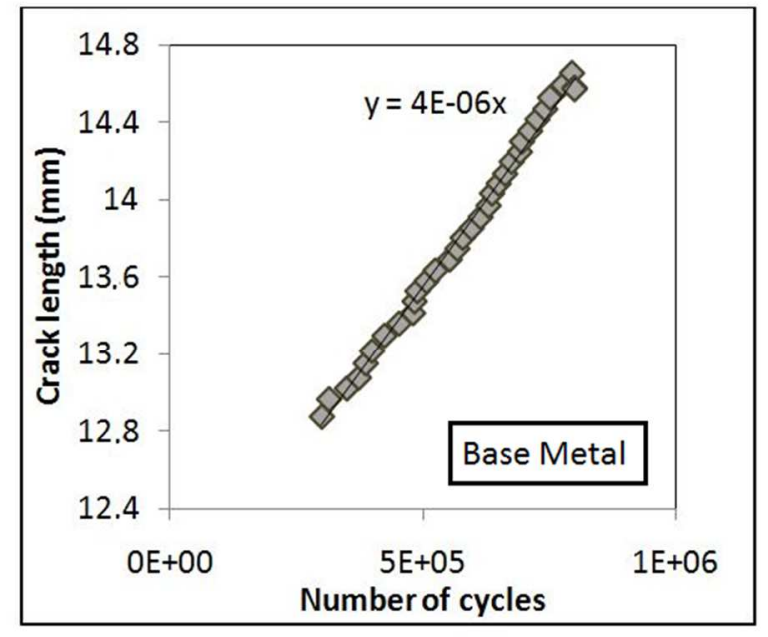

(a)

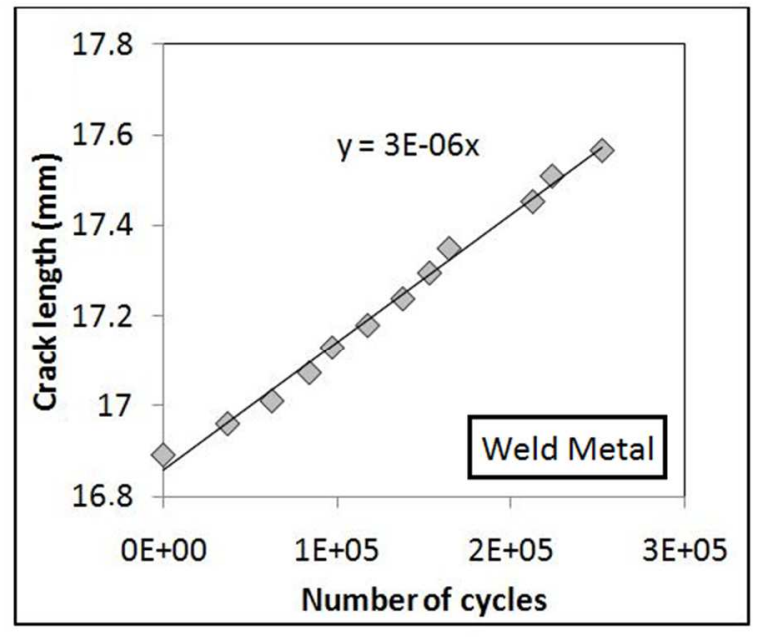

(b)

Figure 18. Crack length evolution against number of cycle for $\Delta \mathrm{K}=20 \mathrm{MPa} \sqrt{\mathrm{m}}, \mathrm{R}=0.1$; a) Base Metal ; b) Weld Metal 


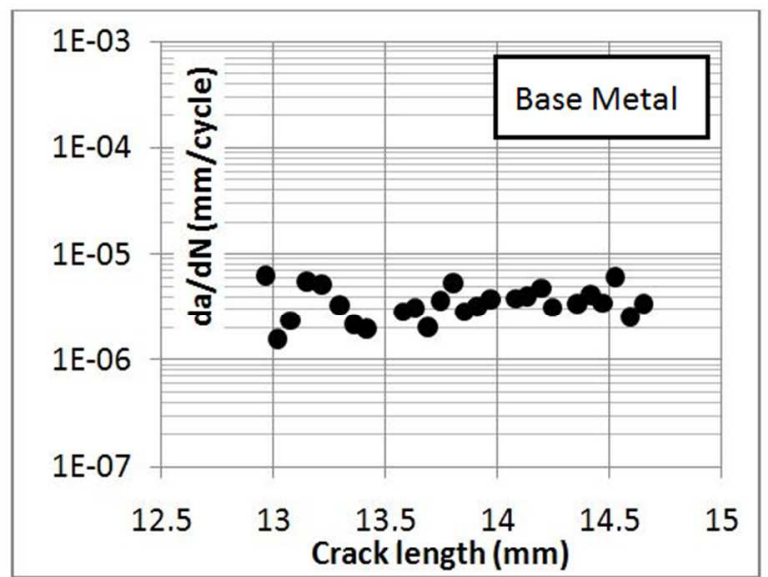

(a)

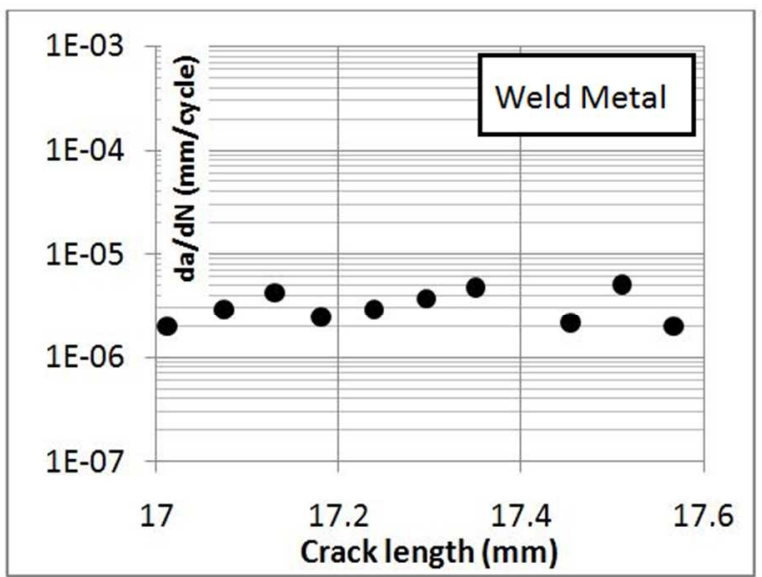

(b)

Figure 19. Crack growth rate evolution for $\mathrm{BM}$ and $\mathrm{WM}$ for $\Delta \mathrm{K}=20 \mathrm{MPa} \sqrt{\mathrm{m}}$; a) Base Metal; b) Weld Metal

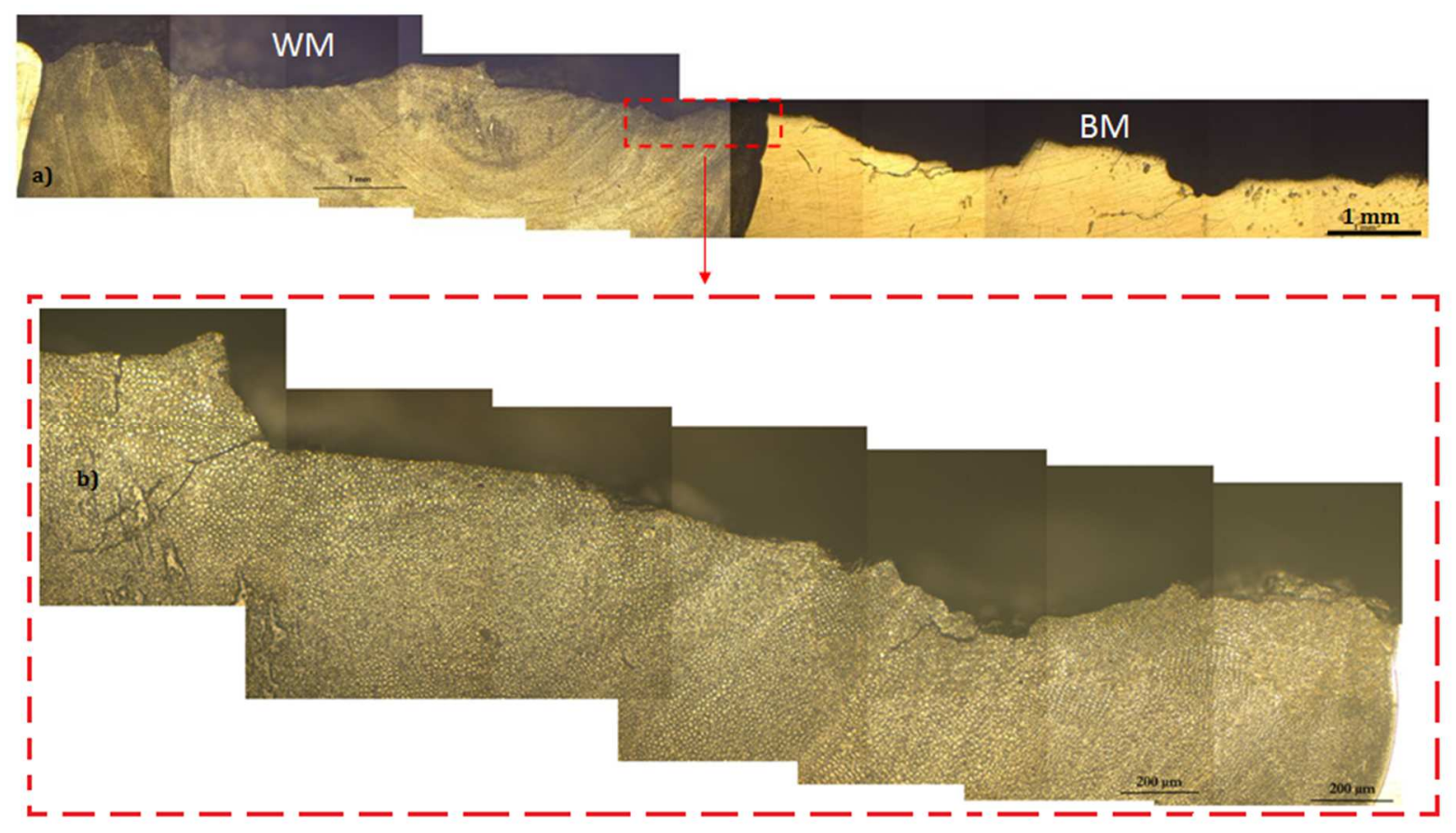

Figure 20. Optical micrograph of CT-WJ crack path in the Weld Metal zone 


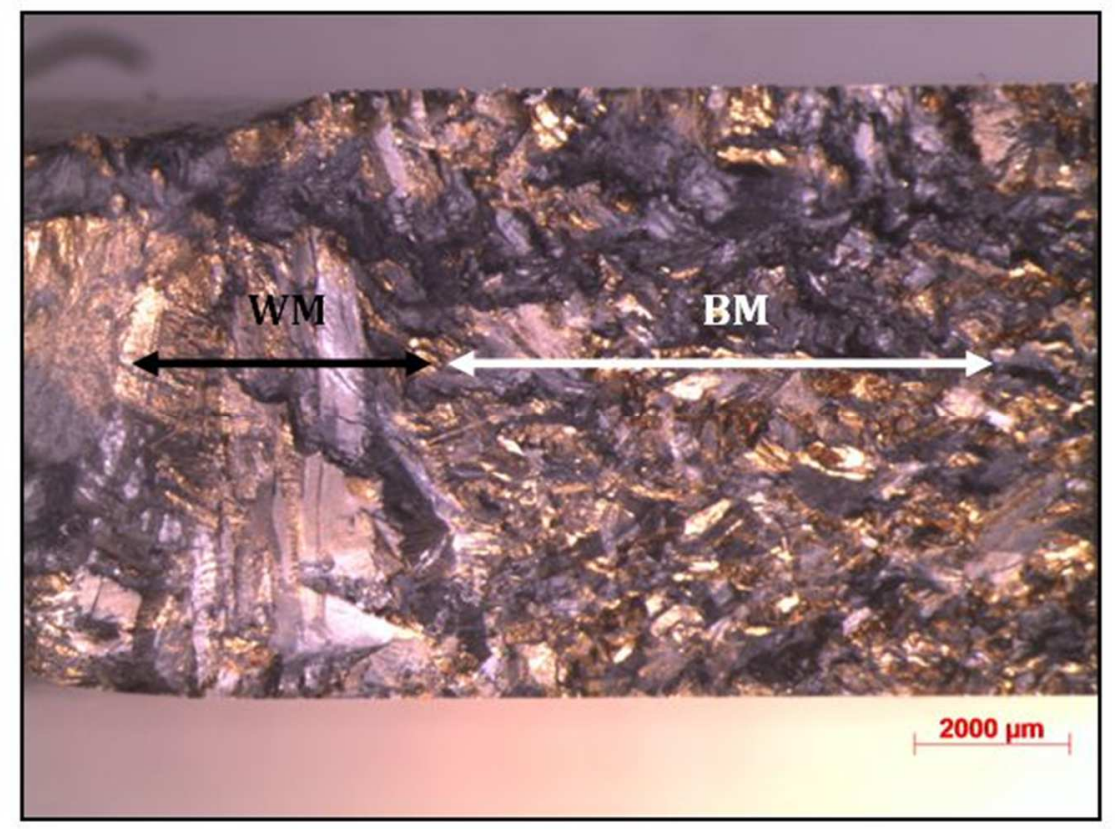

Figure 21. Optical micrograph of fractured surface of Welded Joint specimen

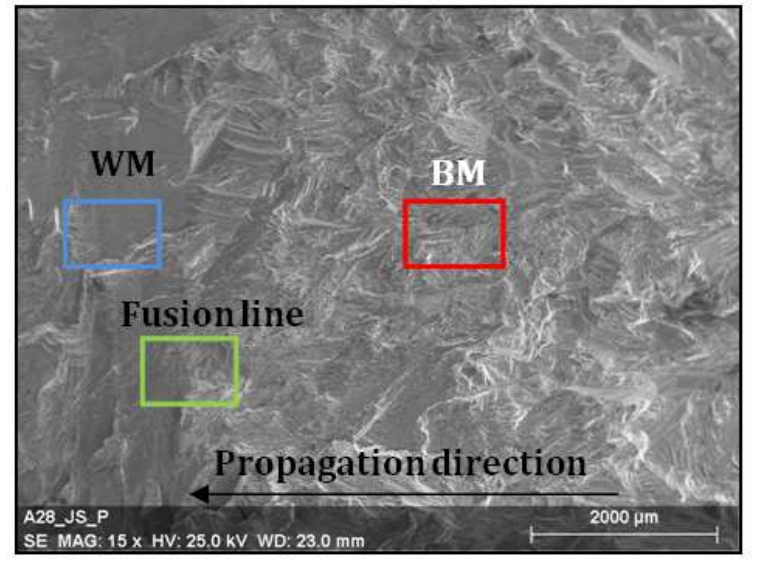

(a)

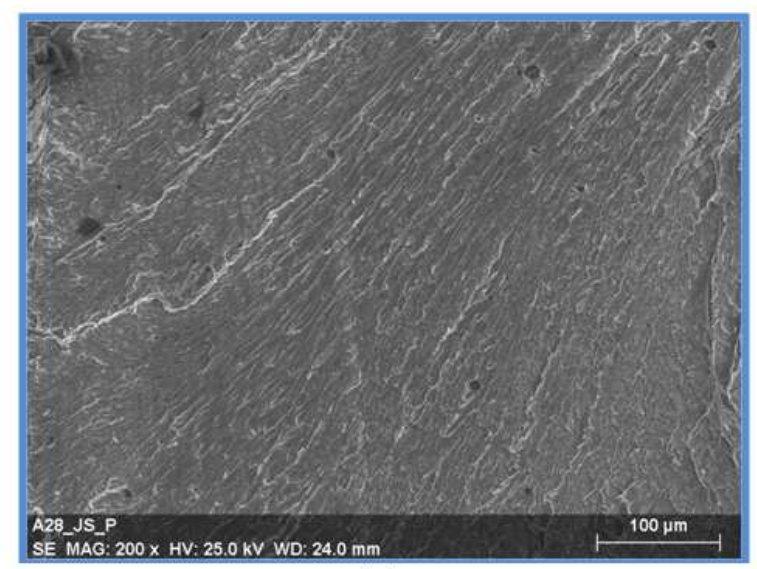

(c)

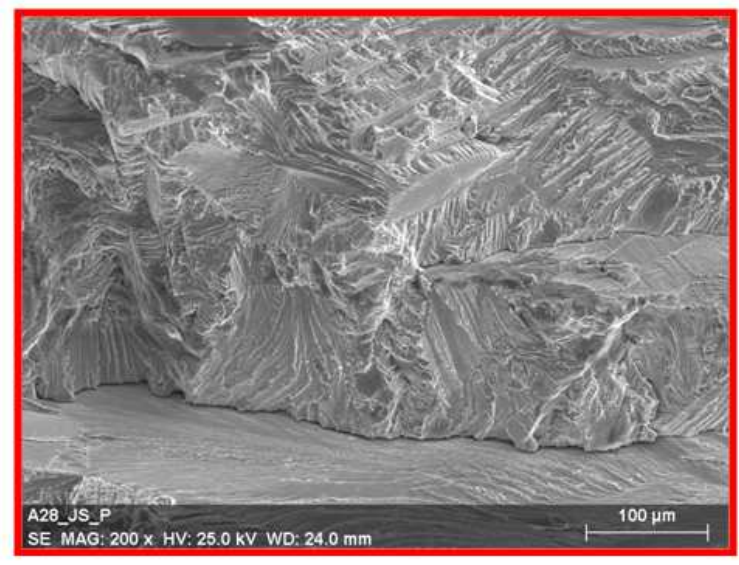

(b)

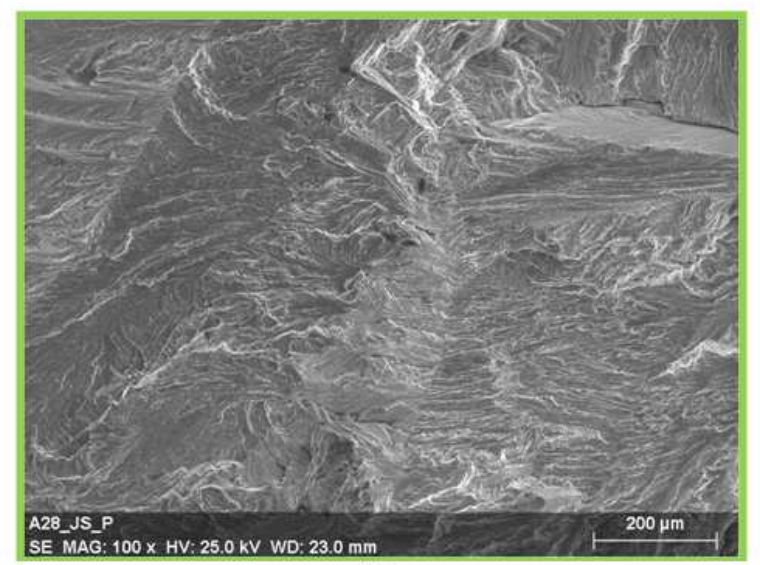

(d)

Figure 22. SEM observation of different zone of fractured surface, Welded Joint specimen; a) general view; b) Base Metal; c) Weld Metal; d) fusion line 
Table 1. Welding parameters for shielded metal arc welding process

\begin{tabular}{|c|c|c|c|c|c|}
\hline $\begin{array}{c}\text { Number of } \\
\text { passes }\end{array}$ & $\begin{array}{c}\text { Filler metal } \\
\text { diameter } \\
(\mathrm{mm})\end{array}$ & Current (A) & Voltage (V) & $\begin{array}{l}\text { Welding } \\
\text { speed } \\
(\mathrm{cm} / \mathrm{min})\end{array}$ & $\begin{array}{c}\text { Heat input } \\
(\mathrm{KJ} / \mathrm{cm})\end{array}$ \\
\hline 1 & 2.5 & 60 & \multirow{5}{*}{26} & 24.6 & 3.8 \\
\hline $2-4$ & \multirow{4}{*}{4} & \multirow{4}{*}{140} & & 29.31 & 7.45 \\
\hline $5-8$ & & & & 31.4 & 6.96 \\
\hline $9-12$ & & & & 33.16 & 6.58 \\
\hline $13-15$ & & & & 32 & 6.81 \\
\hline
\end{tabular}

Table 2. Chemical composition of Base Metal and Weld Metal

\begin{tabular}{cccccc}
\hline $\begin{array}{c}\text { Element } \\
(\mathbf{w t . \%})\end{array}$ & Fe & Ni & Cr & Mo & Si \\
\hline BM & 36.40 & 31.95 & 28.00 & 3.41 & 0.22 \\
\hline WM & 35.85 & 33.36 & 27.00 & 3.14 & 0.64 \\
\hline Filler metal & Bal. & 30.9 & 27.1 & 3.8 & 0.9 \\
\hline
\end{tabular}

Table 3. Paris law parameters of Base Metal specimens

\begin{tabular}{ccc}
\hline $\mathbf{R}$ & $\mathbf{C}$ & $\mathbf{m}$ \\
\hline 0.1 & $6 \times 10^{-15}$ & 4.87 \\
\hline 0.5 & $2.75 \times 10^{-14}$ & 4.84 \\
\hline
\end{tabular}

Table 4. Value of RPZ and da/dN of Base Metal and Weld Metal specimens

\begin{tabular}{ccc}
\hline \multirow{2}{*}{$\boldsymbol{K} \mathbf{K}(\mathbf{M p a} \sqrt{ } \mathbf{m})$} & $\mathbf{r}_{\mathbf{p}}(\boldsymbol{\mu \mathbf { m }})$ \\
\cline { 2 - 3 } & $\mathbf{B M}$ & $\mathbf{W M}$ \\
\hline 11 & 43 & 19 \\
\hline 15 & 80 & 35.5 \\
\hline 20 & 141 & 62.8 \\
\hline
\end{tabular}


Table 5. Paris law parameters of Weld Metal specimens

\begin{tabular}{ccc}
\hline $\mathbf{R}$ & $\mathbf{C}$ & $\mathbf{m}$ \\
\hline 0.1 & $9 \times 10^{-16}$ & 5.28 \\
\hline 0.5 & $4 \times 10^{-14}$ & 4.63 \\
\hline
\end{tabular}




\section{Graphical abstract}
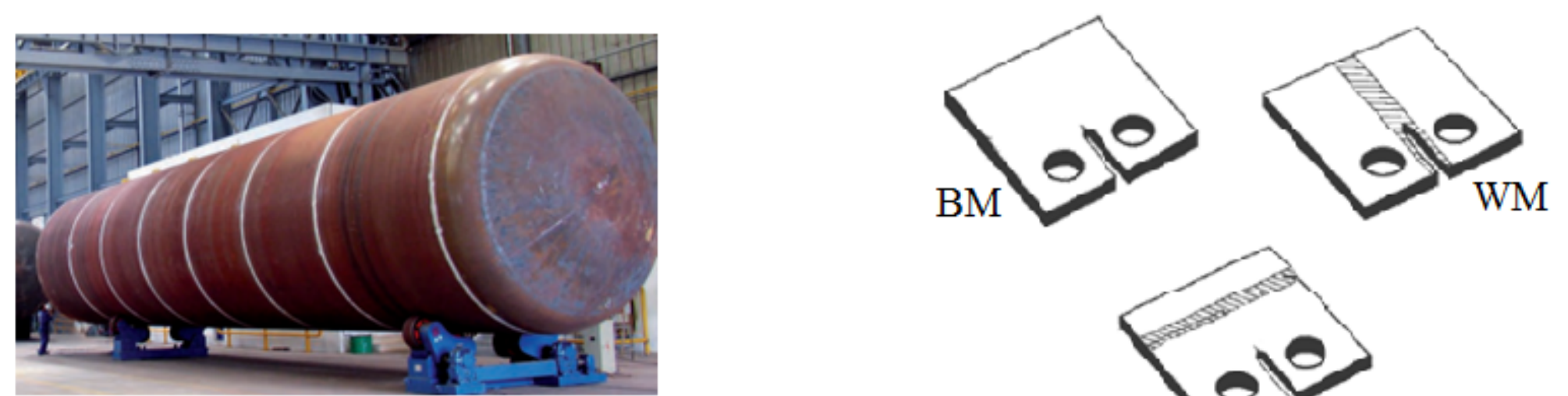

Pressure vessel
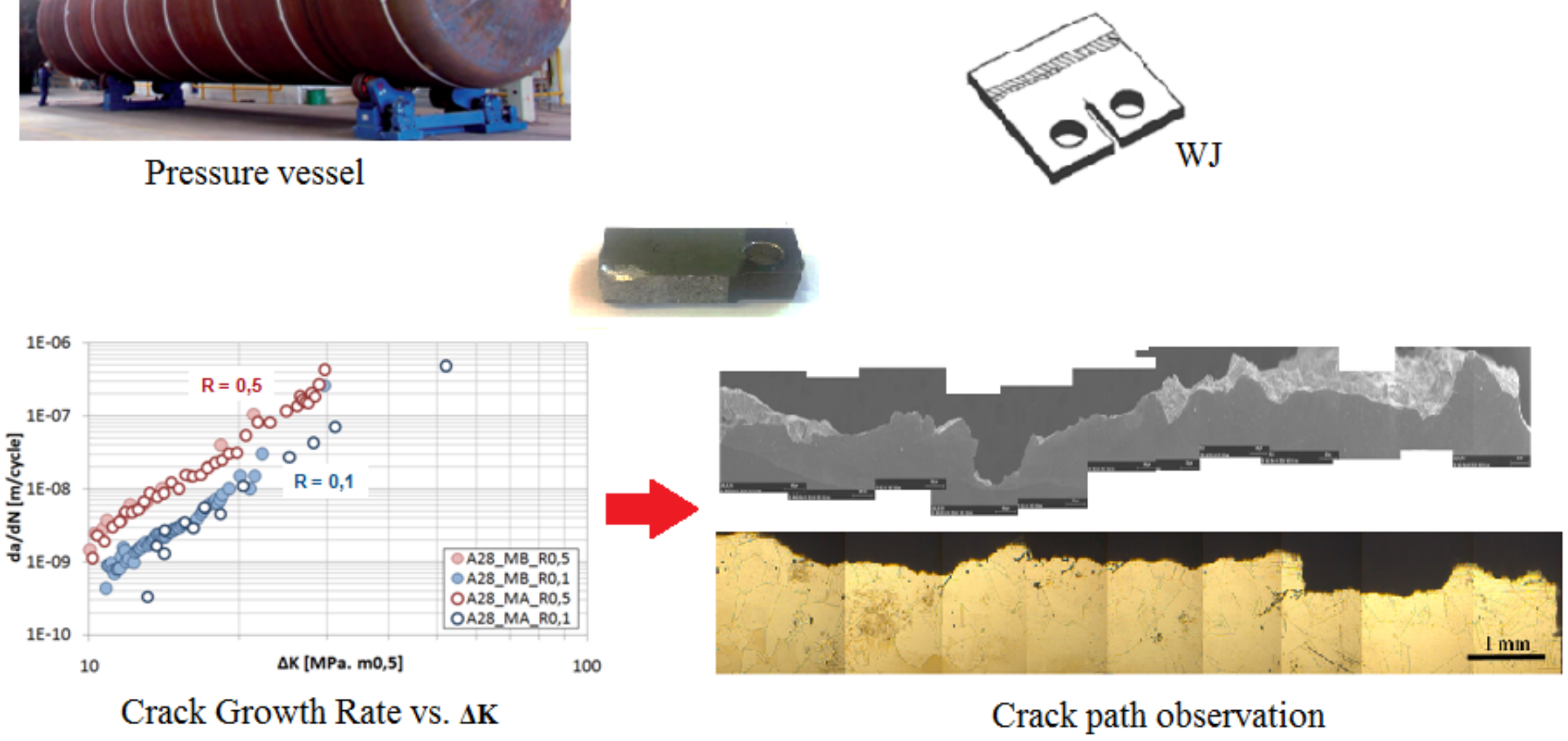